\title{
Working
}

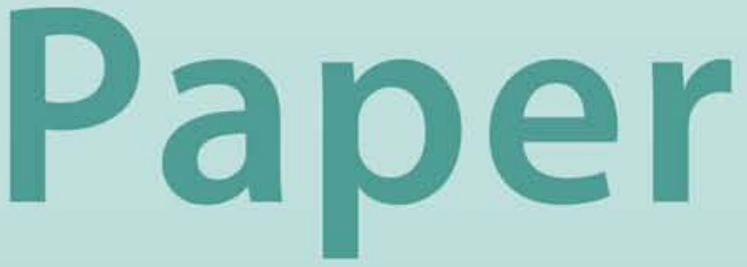


Common Factors in Latin America's Business Cycles

Marco Aiolfi, Luis Catão, Allan Timmermann 


\title{
IMF Working Paper
}

Research Department

\section{Common Factors in Latin America’s Business Cycles}

\author{
Prepared by Marco Aiolfi, Luis Catão, Allan Timmermann ${ }^{1}$ \\ Authorized for distribution by Gian Maria Milesi-Ferretti
}

February 2006

\begin{abstract}
This Working Paper should not be reported as representing the views of the IMF. The views expressed in this Working Paper are those of the author(s) and do not necessarily represent those of the IMF or IMF policy. Working Papers describe research in progress by the author(s) and are published to elicit comments and to further debate.

This paper constructs new business cycle indices for Argentina, Brazil, Chile, and Mexico based on common dynamic factors extracted from a comprehensive set of sectoral output, external data, and fiscal and financial variables spanning over a century. The constructed indices are used to derive a business cycle chronology for these countries and characterize a set of new stylized facts. In particular, we show that all four countries have historically displayed a striking combination of high business cycle and persistence relative to benchmark countries, and that such volatility has been time-varying, with important differences across policy regimes. We also uncover a sizeable common factor across the four economies which has greatly limited scope for regional risk sharing.

JEL Classification Numbers: E32, N10

Keywords: Business Cycles, Factor Models, Latin America

Author(s) E-Mail Address: lcatao@imf.org;

\footnotetext{
${ }^{1}$ We thank Ayhan Kose, Gian Maria Milesi-Ferretti, Adrian Pagan, Valerie Ramey, Luca Sala, Jeffrey Williamson as well as seminar participants at the Fundação Getulio Vargas in Rio de Janeiro, IDB, IMF, the 2005 LACEA meetings, the EHES conference at the Ottoman Bank in Turkey, and at UC San Diego for comments on earlier drafts. We are also grateful to Nathan Balke and Christina Romer for providing us with the U.S. data and Laura Leon and Jane Haizel for editorial assistance. The usual caveats apply.
} 


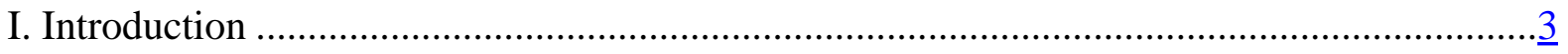

II. Econometric Framework ...................................................................................... $\underline{5}$

A. Model Specification and Dynamic Factor Estimation ..........................................

B. Backcasting Historical Activity Measures with Dynamic Factor Models ................ 2

III. New Business Cycle Indices for Latin America .................................................. 10

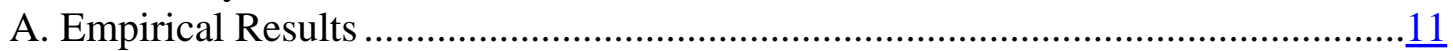

B. Robustness Analysis........................................................................... $\frac{13}{14}$

C. Gains from Using Extended Data Set .......................................................

D. Actual vs. Backcasted Series: A Test Based on U.S. Data ................................15

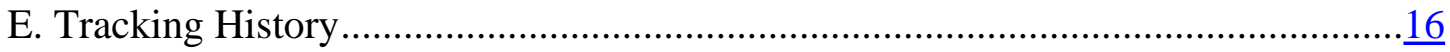

IV. Stylized Business Cycle Facts …................................................................. 18

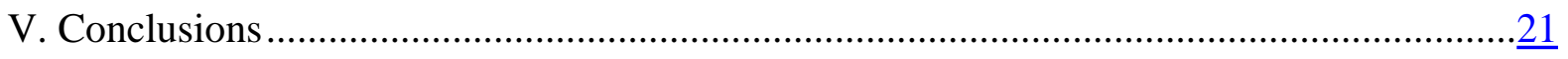

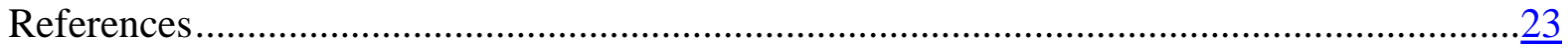

Tables

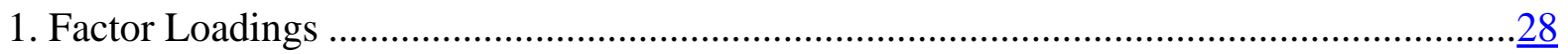

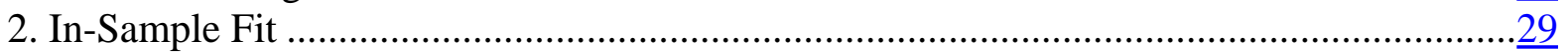

3. In-Sample and Out-of-Sample Fit for the United States............................................ $\frac{30}{31}$

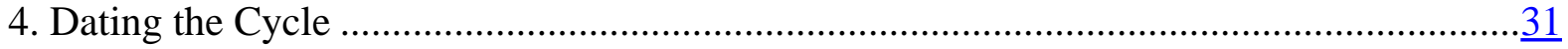

5. Spectral Density Function Estimates of Cyclical Durations ........................................... $\frac{32}{33}$

6. Persistence and Volatility of the Cycle ..................................................................... $\frac{33}{34}$

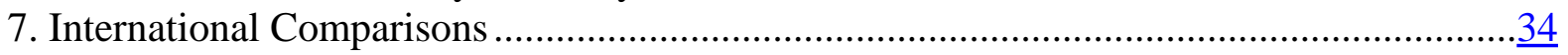

8. Cyclical Volatility Estimates of Selected Variables ..................................................

9. Synchronization of the Latin American Cycles .........................................................

Figures

1. Common Factors .............................................................................................

2. Actual and Backcasted Values of Cyclical Growth .................................................. $\frac{38}{40}$

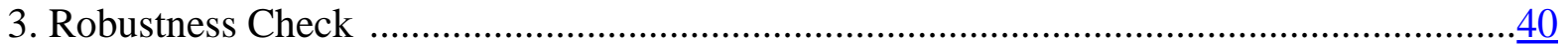

4. Recursive Parameter Estimates ........................................................................... $\frac{42}{43}$

5. Estimates of the First Common Factor .................................................................... $\frac{43}{44}$

6. Actual and Backcasted Values of the US Business Cycle ...........................................44

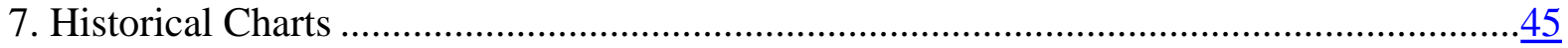

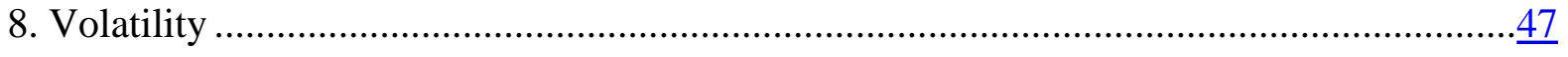

Appendix

I. Data Construction and Sources................................................................................ 


\section{INTRODUCTION}

Business cycle volatility can arise from a variety of sources and be exacerbated by distinct economic policy regimes, possibly reflecting slowly-evolving institutional factors (Acemoglu, Johnson, Robinson and Thaicharoe, 2003) and different degrees of financial and trade openness (Kose, Prasad, and Terrones 2006). This suggests that important insights into the phenomenon can be gained from long-run data spanning a variety of policy regimes and institutional settings. Yet there is a striking dearth of systematic work along these lines for most countries outside North America and Western Europe.

One region that is particularly under-researched is Latin America. This gap is somewhat surprising not only because the region is deemed as highly volatile and the question of what drives such volatility is of interest in its own right; it is also surprising because the region comprises a large set of sovereign nations which have gone through a number of dramatic changes in policy regimes and institutions over a long period of time and relative to other developing countries in Africa and Asia (many of which only became independent nations in recent decades), thus providing a rich context for assessing business cycle theories. Indeed, Latin America is notoriously absent in the well-known historical business cycle studies by Sheffrin (1988) and Backus and Kehoe (1992), and only Argentina is covered in more recent work along similar lines (Basu and Taylor, 1999). Instead, recent research on Latin American business cycles has been either country-specific and covered only short periods of time (e.g. Kydland and Zarazaga, 1997) or focused on specific transmission mechanisms and limited to post-1980 data (Hoffmaister and Roldos, 1997; Neumeyer and Perri, 2005). ${ }^{2}$ A corollary of this gap in the literature is the absence of any formal attempt to establish a reference cycle dating for these countries similar to those available for others-such as the United States and the Euro area-on the basis of a variety of coincident and leading indicators (Moore, 1983; Gordon, 1986; Artis, Kontolemis, and Osborn, 1997; Stock and Watson, 1999).

This paper seeks to fill some of this lacuna. Unlike previous work, we go back as far as available macroeconomic data permit and jointly focus on four of the largest Latin American economies-Argentina, Brazil, Chile, and Mexico. Together, these countries have accounted for some 70 percent of the region's GDP over the past half century (Maddison, 2003, pp. 134-140), thus clearly setting the tone for the region's overall macroeconomic performance. At the same time, data availability for this subset of countries permits us to provide a longrun characterization of the business cycle in these economies similar to that conducted for advanced countries.

\footnotetext{
${ }^{2}$ A notable exception is Engle and Issler (1993) who use the Beveridge-Nelson trend-cycle decomposition to test for the existence of common trends and common cycles in the real GDPs of Argentina, Brazil, and Mexico during 1948-86. They do not provide evidence, however, of what drives the common regional cycle they extract, nor do they look at key variables such as terms of trade or fiscal and monetary shocks that might help explain the observed country-specific movements.
} 
The construction of new indices of economic activity and the identification of volatility sources over such long period allows us to address four main questions. First, how volatile has Latin America been relative to other countries? In particular, has economic activity in Latin America been more or less stable in periods of greater trade and financial integration with the world economy, such as during the pre-1930 gold standard and the post-1980s period? Second, how persistent have macroeconomic fluctuations been in those countries? Since the welfare cost of income fluctuations as well as the burden on stabilization policy rise on volatility and persistence, ${ }^{3}$ these are important questions to ask and document. Third, do we observe similar stylized facts as those documented for other economies that feature in the existing business cycle literature? Finally, is there an identifiable regional business cycle?

As discussed further below, a key requirement for answering these questions is to obtain a measure of economic activity that is expected to be reasonably accurate and consistent over such a long period. We provide this by constructing a new index of economic activity for each of the four countries using a dynamic common factor methodology which, to the best to our knowledge, is for the first time applied to build a business cycle index for this set of countries. This methodology is applied to a uniquely large set of macroeconomic variables compiled from a wide range of historical sources. The data span key sectors such as agriculture, manufacturing, mining and cement production, and include fiscal expenditures and revenues, external variables such as terms of trade, the real exchange rate and import and export volume, as well as a host of financial indicators including interest rates and monetary aggregates. Our index of economic activity is shown to track very closely the existing real GDP data from the full set of national account estimates beginning in the early post-World War II period. Since this index of economic activity is constructed as the common factor that underlies a wide set of macroeconomic and sectorial indicators-thus filtering out idiosyncratic components (including possible measurement errors) - it provides a measure that is germane to the concept of the business cycle as defined in the work of Burns and Mitchell (1946) — which still forms the backbone of the widely used NBER reference cycle indicator for the United States.

The paper's main findings are as follows. Over the full sample 1870-2004, the average business cycle volatility in all four countries was considerably higher than in the advanced economies-albeit with important differences over sub-periods. Latin American volatility was relatively high in the pre-1930 era, during the formative years of key national institutions. It then dropped sharply during the four decades following the Great Depression-an apparent pay-off of the inward-looking growth and highly interventionist policy regimes at a time when volatility in advanced countries rose to all-time highs. Cyclical instability in Latin America bounced back again in the 1970s and 1980s — when it was more than twice as high as the advanced country average- before declining sharply more recently. Throughout the period, cyclical persistence has been high, with large shocks giving rise to a striking

\footnotetext{
${ }^{3}$ For theoretical and empirical evidence on the cost of business cycles see, e.g., Van Wincoop (1999) and Pallage and Robe (2003).
} 
combination of high cyclical volatility and long business cycle durations relative to advanced country standards.

We also find evidence of a number of regularities highlighted in the existing business cycle literature. In particular, external terms of trade have been strongly procyclical, the trade balance counter-cyclical, and fixed investment has been several times more volatile than output. Using the simple gauge proposed in Kaminsky, Reinhart, and Végh (2004), we also find that fiscal policy has been strongly procyclical in these countries. In contrast with evidence more directly supportive of Phillips curve trade-offs among advanced countries, we find that inflation has been historically counter-cyclical in all four Latin American economies. Compared with the more mixed cross-country evidence in other regions, real wages have also been broadly procyclical. Once again, a contrast with advanced economies lies in the strikingly large volatility of these individual variables.

Concordance indices along the lines of Artis et al (1997) and Harding and Pagan (2002) indicate that business cycles in these economies have been reasonably correlated. Pooling data from all four countries, the common factor methodology that we employ permits the identification of a sizeable common regional factor. Since trade linkages between these economies have been small until very recently and capital account linkages remain so to date, global shocks - notably to key foreign interest rates, real income in advanced countries and commodity terms of trade-emerge as key drivers of this common regional business cycle. This result has salient practical implications that have previously been discussed on the basis of distinct methodologies and far more limited data (Calvo, Leiderman, and Reinhart, 1993; Fernandez-Arias, 1994; Agénor et al., 2000; Neumeyer and Perri, 2005).

The remainder of the paper is divided into five sections as follows. Section II lays out the econometric framework and discusses the main estimation issues. Section III reports empirical estimates and provides robustness checks of our methodology, while Section IV presents stylized facts about the business cycle in the Latin American countries. Section V concludes. An appendix contains details of the construction and sources of our data series.

\section{ECONOMETRIC FRAMEWORK}

The idea that a cross-section of economic variables share a common factor structure has a long tradition in economics, dating back at least to the attempt by Burns and Mitchell (1946) to construct an aggregate measure of economic activity. There are two chief motivations for common factor models. First, economic theory suggests strong linkages between economic activity across different sectors due to common productivity, preference and policy shocks. However, since some of these shocks are unobservable, information about them can only be extracted once one has access to a sufficiently large cross-section of economic variables that are at least in part driven by these shocks. Hence, a critical requirement that needs to be met in our analysis is the availability of a broad set of variables that bear sufficiently close relation to aggregate business cycle behavior. Natural candidates include capital formation, government revenue and expenditures, sectorial output series, as well as external trade figures and a host of financial variables. The fact that the Latin American economies have historically been highly dependent on global capital markets and demand from outside 
trading partners suggests that interest rates and cyclical output in advanced countries also be included in the analysis.

The second motivation for using dynamic factor analysis is related to the presence of measurement errors. Activity levels in many sectors are measured with considerable error. Provided that measurement errors are largely idiosyncratic, cross-sectional information can be used to construct more robust common factors that are not similarly sensitive to the impact of such errors. Here one has to make assumptions on the exposure of such observable variables to common shocks in order to identify the underlying driving factors.

Stock and Watson $(1989,2002)$ and Forni, Hallin, Lippi and Reichlin (2000) have shown that the application of dynamic common factor models to a sufficiently representative set of macroeconomic and sectorial indicators provides superior forecasting performance for a target variable such as real GDP or indeed any broad index of economic activity. This methodology turns out to be particularly useful when some of the constituent series that add up to a target variable (such as monthly GDP) are lacking, or when such series are suspected to be mismeasured (as commonly deemed to be the case for certain service activities). An important requirement is that such measurement errors are sufficiently idiosyncratic or that the cross-section of available time series be sufficiently large and/or representative. This methodology is clearly suitable when interest lies in reconstructing (backcasting) historical measures of the cycle, as discussed below.

\section{A. Model Specification and Dynamic Factor Estimation}

Let $\mathbf{X}_{t}$ be a vector of de-meaned and standardized time-series observations on $N$ economic variables observed over the sample $t=1, \ldots, T$. Assuming that $\mathbf{X}_{t}$ admits a dynamic factor representation, we can write

$$
\begin{aligned}
\mathbf{X}_{t} & =\boldsymbol{\Lambda}(L) \mathbf{f}_{t}+e_{t} \\
& =\left[\Lambda_{0, \ldots,} \Lambda_{s}\right]\left[\begin{array}{c}
\mathbf{f}_{t} \\
\ldots \\
\mathbf{f}_{t-s}
\end{array}\right]+e_{t}=\boldsymbol{\Lambda} \mathbf{F}_{t}+e_{t,}
\end{aligned}
$$

where $\mathbf{f}_{t}=\left(f_{1 t, \ldots} f_{q t}\right)$ is a vector of $q$ common dynamic factors, $\Lambda(L)$ is an $N_{x q}$ matrix of filters of length $s, e_{t}$ is an $N x 1$ vector of idiosyncratic disturbances, $\mathbf{F}_{t}=\left(\mathbf{f}_{t}^{\prime}, \ldots, \mathbf{f}_{t-s}^{\prime}\right)$ is an $r \times 1$ vector of stacked factors with $r=q x(s+1)$. Notice that while $q$ identifies the number of common shocks, the dimension of $\mathbf{F}_{t}$ depends on the lag structure of the propagation mechanism of those shocks. Similarly, $\mathbf{f}_{t}$ is the vector of $q$ dynamic factors and $\mathbf{F}_{t}$ is the vector of $r$ static factors, while $\boldsymbol{\Lambda}$ contains the factor loadings. We refer to (1) as the dynamic representation and to (2) static as the static representation. 
In practice the factors are typically unobserved and extraction of them from the observables $\left(\mathbf{X}_{t}\right)$ requires making identifying econometric assumptions. As is typical in the literature, we assume that the errors $\mathbf{e}_{t}$ are mutually orthogonal with respect to $\mathbf{f}_{t}$, although they can be correlated across series and through time. In addition the factors are only identified up to an arbitrary rotation-we explain in the empirical section how we choose a particular rotation using the idea that the factors are only identified indirectly via the factor loadings.

The standard estimation method of dynamic factor models involves maximizing the likelihood function by means of the Kalman filter. This technique has been employed for low-dimensional systems by Stock and Watson (1991). When $N$ is large, non-parametric methods such as static principal components (Stock and Watson (2002)), weighted static principal components (Boivin and $\mathrm{Ng}, 2003$ ) and dynamic generalized principal components (Forni, Hallin, Lippi and Reichlin, 2000) are available for consistent estimation of the factors in approximate dynamic factor models.

Under the assumed orthogonality between the dynamic factors and the idiosyncratic disturbances, we can consider a spectral density matrix or covariance matrix of the $\mathbf{X}_{t}$ decomposition and the common component can be approximated by projecting either on the first $r$ static principal components of the covariance matrix (Stock and Watson, 2002) or on the first $q$ dynamic principal components (Forni, Hallin, Lippi and Reichlin, 2000), possibly after scaling the data by the covariance matrix (Boivin and $\mathrm{Ng}$ (2003)). In this paper we consider both approaches and evaluate the robustness of the results to this choice, since there is no clear-cut evidence on which approach is superior. ${ }^{4}$

In Stock and Watson (2002), a principal component estimator of the factors emerges as the solution to the following least squares problem:

$$
\min _{F, \Lambda} T^{-1} \sum_{t-1}^{T}\left(\mathbf{X}_{t}-\mathbf{\Lambda} \mathbf{F}_{t}\right)^{\prime}\left(\mathbf{X}_{t}-\mathbf{\Lambda} \mathbf{F}_{t}\right)
$$

subject to the restriction $\boldsymbol{\Lambda}^{\prime} \boldsymbol{\Lambda}=\mathrm{I}$. The solution to this problem $\left\{\hat{\boldsymbol{\Lambda}}, \hat{\mathbf{F}}_{t}\right\}$ takes the form

$$
\begin{gathered}
\hat{\boldsymbol{\Lambda}}=v \\
\hat{\mathbf{F}}_{t}^{S W}=v^{\prime} \mathbf{X}_{t,}
\end{gathered}
$$

\footnotetext{
${ }^{4}$ In their empirical forecasting comparison, D'Agostino and Giannone (2004) find that weighted procedures generally produce better forecasting performance. Similarly, Boivin and $\mathrm{Ng}$ (2003) find that weighted principal components improve on the forecasts of the standard principal components methods applied to the static factor model. Stock and Watson (2005) report that forecasts based on factors estimated with static principal components and those estimated with weighted principal components tend to be highly correlated.
} 
where $v$ is an $r \times 1$ vector of eigenvectors corresponding to the $r$ largest eigenvalues of the variance-covariance matrix of the $\mathbf{X}$ variables, $\boldsymbol{\Sigma}_{x x}$. The resulting estimator of the factors, $\hat{\mathbf{F}}_{t}^{S W}$, is the first $r$ static principal components of $\mathbf{X}_{t}$.

In Forni et al (2000) the dynamic structure in the factors is explored by extracting principal components from the frequency domain. Their approach permits efficient aggregation of variables that may be out of phase, with the common component being estimated by projecting the $\mathbf{X}$-variables on present, past and future dynamic principal components. The factors and their loadings are the solution to the following non-linear least squares problem that weights the idiosyncratic errors by their covariance matrix, $\left.\mathbf{\Omega}=\mathrm{E}\left(\mathbf{X}_{t}-\mathbf{\Lambda F}_{t}\right)\left(\mathbf{X}_{t}-\boldsymbol{\Lambda F}_{t}\right)^{\prime}\right]^{\prime}$ :

$$
\min _{F, \Lambda} T^{-1} \sum_{t-1}^{T}\left(\mathbf{X}_{t}-\mathbf{\Lambda} \mathbf{F}_{t}\right)^{\prime} \Omega^{-1}\left(\mathbf{X}_{t}-\mathbf{\Lambda} \mathbf{F}_{t}\right)
$$

again subject to $\boldsymbol{\Lambda}^{\prime} \boldsymbol{\Lambda}=\mathrm{I}$. As in Forni et al (2003), we adopt a two-step weighted principal component estimation procedure where $\boldsymbol{\Omega}$ is estimated as the difference between the sample covariance matrix, $\hat{\boldsymbol{\Sigma}}_{x x}$, and the dynamic principal components estimator of the spectral density matrix of the common components. ${ }^{5}$

The resulting estimators of the loadings and common factors are

$$
\begin{aligned}
& \hat{\Lambda}=v_{g} \\
& \hat{\mathbf{F}}_{t}^{F H L R}=v_{g}^{\prime} \mathbf{X}_{t}=v^{\prime} \tilde{\mathbf{X}}_{t},
\end{aligned}
$$

where $v_{g}$ are the generalized eigenvectors associated with the largest generalized eigenvalues of the estimated covariance matrices of common and idiosyncratic components and the resulting estimator of the factors is the vector consisting of the first $r$ generalized principal components of $X_{t}$. This can be seen as the first $r$ static principal components of the transformed data $\tilde{\mathbf{X}}_{t}=(\hat{\mathbf{\Omega}})^{-1 / 2} \mathbf{X}_{t}$.

\footnotetext{
${ }^{5}$ Specifically, let $\mathbf{x}_{t}$ denote the standardized values of $\mathbf{X}_{t}$. The estimated spectrum of $\mathbf{x}_{t}, \mathbf{S}_{x x}(\omega)$, is computed at 101 equally spaced ordinates using a Bartlett kernel applied to $p=T^{1 / 2}$ sample autocovariances. The estimated spectrum of the dynamic factor components, $\mathbf{S}_{f f}(\omega)$, is computed for each of the 101 frequencies using $q$ dynamic principal components of $\mathbf{S}_{x x}(\omega)$. The estimated value of $\boldsymbol{\Omega}$ is computed as $\boldsymbol{\Omega}=\boldsymbol{\Sigma}_{x x}-\boldsymbol{\Sigma}_{f f}$, where $\boldsymbol{\Sigma}_{x x}$, is the sample second moment matrix of $\mathbf{x}$ and $\boldsymbol{\Sigma}_{f f}$ is the inverse fourier transform of $\mathbf{s}_{f f}(\omega)$.
} 
An important requirement when applying these estimators is that all the variables entering the dynamic common factor specification are stationary. With the exception of the inflation rate, real interest rates, and the ratios of export to import value which are stationary by construction, we employ two alternative approaches to ensure stationarity. One is the standard Hodrick-Prescott filter, with a smoothing factor set to 100, as is common practice with annual data (e.g. Backus and Kehoe, 1992; Kose and Reizman, 2001). The second approach to detrending considered here is the symmetric moving average band-pass filter advanced by Baxter and King (1999). Following common practice with annual data, we set the size of the symmetric moving average parameter to three but use a larger-than-usual bandwidth ranging from 2 to 20 years so as to avoid filtering out the longer (12-20 year) prewar cycles first documented by Kuznets (1958) for the United States and found to be present in several advanced countries (Solomou, 1987). As shown below, both detrending methods yield very similar results.

\section{B. Backcasting Historical Activity Measures with Dynamic Factor Models}

The common factors derived above, $\hat{\mathbf{F}}_{t}^{S W}$ or $\hat{\mathbf{F}}_{t}^{F H L R}$, are of interest in their own right since they provide broad-based measures of economic activity. However, often particular interest lies in analyzing a particular time-series such as real GDP over long periods of time. However, data on this variable may only be available over a more recent sample. and, even when available, the series may be subject to considerable measurement error.

The common factor approach is ideally suited to handle these problems provided that the variable of interest lends itself to a similar dynamic factor representation as assumed above. Letting the real GDP cycle be represented by the variable $\gamma^{t}$, and under the assumption that $\gamma^{t}$ is driven by the common factors $\mathbf{f}_{t}=\left(f_{l t}, \ldots, f_{q t}\right)^{\prime}$ derived above, we have

$$
y_{t}=c+\mathbf{b}(L) \mathbf{f}_{t}+\varepsilon_{t}
$$

Our interest lies in backcasting values to create a new historical time-series of cyclical aggregate output so we estimate the following backcasting equation using contemporaneous factor values:

$$
y_{t}=\alpha+\boldsymbol{\beta} \hat{\mathbf{F}}_{t}+\varepsilon_{t}
$$

When data of sufficient quality on $y_{t}$ are only available over a much shorter (recent) sample than data on the variables used to construct estimates of the factors, under the maintained model (5), we can estimate the parameters $\theta=\{\alpha, \beta\}$ over a (recent) sample period for which quality data are available on output, $\gamma$. We can then backcast cyclical output over the longer sample for which estimates of the factors are available. In the following we explain details of how we set up the data and how we deal with estimation issues pertaining to the number of factors and parameter instability. 


\section{NEW BUSINESS CYCLE INDICES FOR LATIN AMERICA}

A full set of national income account data for Argentina, Brazil, Chile and Mexico is only available from the mid-1930s (Argentina) or starting at some point in the 1940s for the other three countries. ${ }^{6}$ Previous researchers have tried to overcome this limitation by constructing proxy measures of economic activity for the earlier period. The quality of these constructs is, however, very uneven due to the lack and/or the very poor quality of output data for broad sectors of the economy. In the case of Argentina and Brazil, for instance, official output data in agriculture, manufacturing, construction, and services only become available from 1900 onwards and, even then, with serious gaps particularly in the case of Brazil (c.f. Haddad, 1978). With regard to Chile and Mexico, sectorial output data stretching back to the 19th century are more readily available but, again, often spanning a small subset of the universe of firms and of questionable quality (see the Appendix). Insofar as previous researchers tried to derive an aggregate measure of economic activity from averages of these production data (resorting to linear interpolation to fill gaps in some discontinuous annual series), the resulting indices are bound to be highly inaccurate. While two other attempts have been made to overcome these problems, they have clear drawbacks. One is that of backcasting Argentine GDP based on a handful of production and trade variables by means of linear OLS regressions (della Paolera, 1989, p.189); the other is the use of static common components to backcast 19th century Brazilian GDP on the basis of foreign trade data (Contador and Haddad, 1975). ${ }^{7}$ Despite this very limited variable span, the latter series has been (misleadingly) compiled by Maddison (1995, 2003) and Mitchell (2003) as a reliable indicator of pre-war Brazilian GDP.

Our paper addresses these data limitations by substantially broadening the number of variables from which one can derive valuable information on the pace of aggregate economic activity. We take into account not only production or foreign trade variables, but also monetary and financial indicators that economic theory suggests should be correlated with the business cycle. As discussed in the Appendix, the data were obtained from an extensive compilation of both primary and secondary data sources. In some cases this resulted in entirely new series being created; once combined with their counterparts from the later 20th century, these series span the entire 1870-2004 period. Still, as one might expect from country-specific idiosyncrasies in data collection (especially before the standardization of national account and balance of payments methodologies), the availability of macroeconomic and financial indicators varies somewhat across countries. For example, for Mexico very few variables were measured prior to 1877 , so our business cycle index for that country only

\footnotetext{
${ }^{6}$ Even for Argentina, full-fledged information underpinning national account estimates is not available before 1950 (see Banco Central de la Republica Argentina, 1976). In the case of Mexico, a GDP series constructed solely on the basis of sectoral output information-and not based on expenditure and income data-has been reported by Banco de Mexico since 1921.

${ }^{7}$ A cruder attempt of reconstructing 19th century Brazilian GDP can be found in Goldsmith (1986), who derives a GDP growth series based on an unweighted average of government expenditure, revenues, wages, exports and imports.
} 
starts in 1878. Likewise, it proved impossible to obtain any meaningful series for manufacturing and agriculture output in Brazil before 1900, although we were successful in filling the gap regarding domestic cement consumption (a proxy for construction activity) as well as output in the transportation and communication sectors. A similar gap was filled for pre-1900 Argentina which also benefited from the use of a new proxy indicator of manufacturing activity starting in 1875 and recently compiled by Della Paolera and Taylor (2003).

Overall, we were able to put together a panel of between 20 to 25 time series per country which, as shown below, appears to provide an excellent gauge of the respective national business cycles. The Appendix provides a detailed discussion of measurement issues underlying the various series and the respective data sources. Since we are concerned with real economic aggregates, all variables are measured in real terms deflated by the consumer price index or by the investment or GDP deflators as appropriate-the obvious exceptions being inflation, the ratios of exports to imports, and country spreads (as measured by the difference between the yield on a sovereign foreign-currency denominated bond and the respective U.K. or U.S. yields). ${ }^{8}$

\section{A. Empirical Results}

Factors extracted from a dataset comprising information on a variety of variables are not typically straightforward to interpret. Nevertheless, the estimated factor loadings do offer important clues in this respect. While factors are only identified up to an arbitrary rotation, it becomes clear from the individual factor loadings that the first factor bears a strong positive correlation with the GDP cycle during periods for which actual GDP data is available.

Table 1 shows the estimated factor loadings for the first two factors extracted using the Stock and Watson procedure and the HP-detrending since the results using other methods yield very similar estimates, as shown below. We report only the first two factors since the addition of further factors only contributes marginally to the total variance of the panel with the exception of one country (Brazil) for which the third factor is important (more on this below). The first factor (labeled F1) can be interpreted as a broad measure of cyclical activity since it loads positively on indicators that are well-known to be procylical such as sectorial output, fixed capital formation, import quantum and real money, all measured in deviations from their respective long-term trends. The interpretation of the second factor $(\mathrm{F} 2)$ is less clear-cut. For Argentina, Brazil and Chile, this factor assigns large loadings to money, the domestic interest rate and the real exchange rate (also entered in deviations from trend).

\footnotetext{
${ }^{8}$ In the case of interest rates, we employ the commonly used method of defining the real interest rate as the difference between the nominal interest rate and current inflation. Since all interest rate series used in the estimation refer to short-term instruments, discrepancies arising from possible mismatches between current and expected inflation are less critical than in the case of long bonds. Yet, we also checked the robustness of our results to the use of the U.S. 10-year bond yield instead of the 3-month U.S. treasury bill and found that this did not have any effect on inferences made.
} 
Thus, it can be broadly interpreted as an index of monetary conditions. In the case of Mexico, the largest loadings are observed on the variables capturing external linkages such as the terms of trade, the real exchange rate or import volume. This is suggestive of an important difference between the economies, possibly indicating that Mexico's linkage to the U.S. economy is of special relevance-a conjecture that is corroborated by further evidence presented below.

Figure 1 plots the two SW factors for each of the countries using the HP detrending as reported in Table 1. For comparison, we also plot the same factors using band-pass filter detrending. Since the two approaches yield very similar results and given that the HPdetrending has been more extensively used in related studies (Backus and Kehoe, 1992; Kydland and Zarazaga, 1997; Kose and Reizman, 2001; Neumeyer and Perri, 2005), we maintain this detrending method through the remainder of the paper.

While the factors are of interest in their own right, ultimately our interest lies in reconstructing a measure of cyclical activity in the Latin American economies. To this end, Table 2 reports the $\bar{R}$ - value of regressions of de-trended actual GDP on the factors across a range of factor model specifications. The results cover the period 1950-2004, when full national account estimates are available for all four countries. As with the bulk of the series entering the alternative factor specifications, actual GDP is also expressed in deviations from an HP trend-a widely used measure of the output gap. Correlations in Table 2 thus gauge the extent to which the various factor models span the real GDP cycle. To indicate the sensitivity of the results to the adopted econometric methodologies, we present results both for the all-regressor approach-which maximizes the $R^{2}$ by projecting cyclical GDP on all variables - and a range of alternative factor approaches such as the Stock and Watson approach using between one and four common factors and the Forni et al (2000) approach estimated with up to two dynamic factors and up to four static factors. As we shall see later, the high in-sample fit of the all-regressor, "kitchen sink" approach comes at the cost of overfitting the data and producing poor out-of-sample performance.

The linear projections of the GDP cycle on the various factors yield a tight fit for Argentina, with $\bar{R}^{2}$ - values varying from 0.89 for the all-regressor approach to around 0.80 for the two factor approaches. Correlations are also generally high for Chile and Mexico, with 75-85 percent of the variance of the real GDP cycle explained by the first two factors. The fit for Brazil is relatively worse overall, but by including the series on agricultural and manufacturing output (both of which are only available from 1900 onwards), one can raise it to above 70 percent using the SW and FHLR approaches, c.f. panel B of Table 2.

Further evidence that the various approaches tell a similar story can be gleaned from Figure 2 , which show the backcast estimates of cyclical GDP in the four economies. In each case the upper panel plots our estimates and (where available) other estimates of cyclical GDP over the period 1870-1950, while the bottom panel shows the corresponding values for the remaining part of the sample. The close proximity between the fitted and actual values for the post-war period is clear from these plots-visual differences only emerge during rare and extremely large spikes such as in Brazil in 1961-62 and 1980. Overall, however, it is plain that: (i) the estimated values closely track actual cyclical GDP whenever this is available; (ii) the various factor approaches generate quite similar estimates of the cycle and (iii) factor 
estimates often differ substantially from estimates based on the all-regressor least squares approach which is the furthest away from "actual" values, as judged by the observations from better quality estimates of actuals out-of-sample (as for Argentina over 1935-49, Chile during 1940-49, and Mexico 1925-49). ${ }^{9}$ This strongly cautions against the use of a kitchen sink approach by researchers in the reconstruction of earlier GDP data.

\section{B. Robustness Analysis}

It is important to investigate whether our estimates are robust to potential instability of the factor loadings and to changes in the factor specification. The common factor projections were built under the assumption that factor loadings remain constant over time. In the same way that out-of-sample forecasts rely on an implicit assumption that certain relationships between predictor variables and the target variable remain constant over the forecasting period, backcasting economic activity measures without this assumption is infeasible.

An advantage of our approach is that the use of common factors can be expected to be reasonably robust against the structural instability that plagues low-dimensional forecasting regressions. Stock and Watson (2002) provide both theoretical arguments and empirical evidence that principal component factor estimates are consistent even in the presence of temporal instability in the individual time-series used to construct the factors provided that this instability averages out in the construction of the common factors. This occurs if the instability is sufficiently idiosyncratic to the various series.

To evaluate the robustness of our results for the backcasted GDP values, Figure 3 plots the minimum and maximum value across different specifications of the backcasting equation. In particular, we consider:

- $\quad$ Two different estimation samples for the backcasting equation, 1915-2004 and 1950-2004 (GDP data for Chile and Mexico are available only after 1940 so for these countries the backcasting equation is estimated only over the sample 1950-2004.)

- Six different factor specifications: $S W(r), r=2,3$ (where $r$ is the number of static factors), $\operatorname{FHLR}(q, r)$, where the first argument, $q$, is the number of dynamic factors while the second, $r$, is the number of static factors. We set $(q, r)=(2,1),(3,1),(2,2)$ and $(2,3)$.

\footnotetext{
${ }^{9}$ The gaps between the "other" and our backcast estimates for Brazil before 1930 is not surprising since the reported pre-1930 estimate by Haddad (1978) is constructed with very incomplete sectoral data, giving excessive weight to highly cyclical subsectors (like crop production) at the expense of less cyclical ones (like services), in addition to relying extensively on interpolation to fill some gaps. Given the reasonably tight fit between our index and the official GDP data after 1950, we suspect that those differences reflect the inaccuracies of the Haddad index rather than of our index, which relies on information across a wider spectrum of variables.
} 
- Different samples for factor estimation, where a new sample is adopted if new time series become available (Argentina: 1870-2004, 1875-2004, 1900-2004; Brazil: 1870-2004, 1900-2004; Chile: 1870-2004; Mexico: 1878-2004).

- $\quad$ Two different panels of data, one including the external variables while the other excludes these.

The sensitivity analysis produces 72 specifications for Argentina, 36 for Brazil and 12 for Chile and Mexico. With the exceptions of Brazil in 1890-91, 1986 and 1989, Chile in 192932 and Mexico in 1916, the range is very narrow; and even for those outlier observations, all estimates point in the same direction. As it turns out, all indications are that little has changed over time. This congruence would be unlikely to hold if the factor loadings were subject to structural breaks or considerable instability.

In addition, we have also checked for the stability of coefficients in the regression of the factors on the cyclical component of real GDP (equation (5)). This was done by re-estimating the regression (5) for the period 1961-2004 (instead of 1950-2004) and recursively rolling back the estimation to the last point for which reasonably reliable data on real GDP exists. ${ }^{10}$ The results plotted in Figure 4 show that the backcasting equation coefficients are reasonably stable over the 1930-60 period (1940-60 for Chile); only in the case of Mexico between 1921 and 1925 is there evidence of some instability. But since the real GDP figures used to compute the recursion over the period in the early postrevolutionary period for Mexico are likely to be marred by measurement problems before the Banco de Mexico centralized the compilation of macroeconomic data in 1925, this should not be surprising.

Overall, the results above make a simple but important point. Even when the common factors are extracted from a dataset containing a limited number of series on output growth, they track the real GDP cycle well. This may not be overly surprising since we selected variables that economic theory suggests should be closely related to cyclical activity. Yet, this evidence underscores the robustness of backcasting inferences on the aggregate output cycle once they are based on a sensible combination of fiscal, financial, sectorial and external variables.

\section{Gains from Using Extended Data Set}

Although our results do not appear to be sensitive to the particular choice of factor estimation methodology, number of factors or sample period used to estimate the factor loadings or

\footnotetext{
${ }^{10}$ While, as discussed in the text, pre-war data on GDP for all the countries are considerably less reliable than post-war official data, we thought it would still be worthwhile to compare the stability of the backcasting regression coefficients against some of the existing pre-war data as a further robustness check. Given that data for Argentina, Brazil and Mexico from the 1920 onwards appear to be of much better quality (albeit still relying on partial production data) than pre-1920 data, we extended this recursive stability test to 1920 using this data.
} 
projection coefficients, one might ask what the value-added is of using as wide a set of variables as that adopted here when constructing the common factors. To answer this, we compare in Figure 5 plots of the first common factor constructed using our extensive data set on sectoral output, financial, fiscal and trade variables against that using only sectoral output variables. Common factors based exclusively on sectoral output data are far smoother than those based on the wider set of variables. This shows up in a failure of the more narrowly constructed common factors in fully accounting for the depth of the crises in Argentina in 1918 and 1990, in Brazil and Mexico following World War I and in Chile following the Great Depression. In addition many of the smaller peaks and troughs—such as the cycle around 1900 in Argentina-are entirely missed by the common factor based on sectoral output information.

This limitation of the smaller set is not exclusive to Argentina for which we have only two sectoral variables going back to 1870. Adding industrial output for Argentina (a series that becomes available from 1875) does not overturn this conclusion. Significant gaps also arise for Brazil, Chile, and even Mexico which has a wider sectoral output data coverage back to the 1870s. Discrepancies between the two series are not exclusive to the pre-war period, and hence do not seem entirely attributable to the poorer quality of earlier data; large gaps emerge, for instance, for post-1960 Brazil.

These plots vividly demonstrate the importance to the construction of broad measures of economic activity of using a wide and varied set of economic variables representing not just a few sectoral output series. In other words, fiscal, financial and external trade variables play an important role in filling the gap.

\section{Actual vs. Backcasted Series: A Test Based on U.S. data}

Skeptical readers might object that we have not, so far, provided any direct evidence that our approach works well in terms of backcasting the cycle. This is true in the sense that the same absence of reliable and broad based historical data on output in Latin America that motivated our analysis also makes it impossible for us to compare our fitted values against realized observations.

To address this concern, we used our approach on the U.S. pre-war cycle. Since the United States has high quality real GDP estimates going back to 1870 , we can directly compare model predictions and "actual" values (or, to be precise, reasonably accurate estimates of the "actual" value). For this test to be informative for our analysis, it is important that we use a set of U.S. variables similar to those used for the four Latin American countries, even though much greater data availability for the United States would have allowed us to include many more variables in the estimation of the factor model. With this consideration in mind, we stack the deck against our approach by backcasting the U.S. pre-war cycle based on an even smaller set of variables (18 in total, as described in the Appendix) than those for the four Latin American countries. 
Table 3 reports the $R^{2}$ - values of the various estimation methods. ${ }^{11}$ The fit of the various factor models over the 1950-2004 period is very good, with $\bar{R}^{2}$ - values around 0.80 . The last column also indicates that our backcasted cycle closely tracks Balke and Gordon's (1989) revised estimate of U.S. real GDP, which we detrend by an HP filter and plot in Figure 6 together with our estimates. ${ }^{12}$ Clearly the fit is not perfect-with the largest discrepancy emerging during the World War II boom; yet, the overwhelming majority of cyclical turning points is consistently picked up by both indices. ${ }^{13}$

This exercise indicates that application of our backcasting methodology to a sufficiently representative set of macroeconomic and sectoral variables can yield a very close proxy of actual cyclical fluctuations in U.S. real GDP. To the extent that the in-sample fit for the postwar period is even higher for some of the Latin American countries shown above-and recalling that the span of variables is larger - this suggests that our approach is very likely to be picking up turning points and cyclical variations in these economies quite accurately.

\section{E. Tracking History}

As a final robustness check we ask how well the backcasted series square with qualitative historical evidence on events deemed to be major economic turning points in these countries. Figure 7 relates the two. Starting with pre-war Argentina, the index picks up all economic downturns associated with well-known world events-notably the stock market crashes in Europe and the U.S. in 1873 and the ensuing global economic depression, the 1890 Barings crisis, the 1907 financial panic, the two world wars, and the Great Depression of the 1930s. Likewise, major post-WWII shocks are also conspicuously picked up as turning points in our index, notably the boom and bust in world commodity prices associated with the Korean War in the early 1950s, the oil price shocks of the 1970s, the early 1982-83 debt crisis, as well as the emerging market crises of the 1990s (the 1994-95 "Tequila" crisis and the Asia and Russia crises of 1997-98). A glance at Figure 7 also indicates that such a juxtaposition of

${ }^{11}$ The loadings of the fitted model over 1870-2004 are not reported to conserve on space but are available from the authors upon request.

12 As shown in Table 3, using Romer's (1989) lower volatility estimate of U.S. pre-1929 GDP, the fit is less tight but only slightly so. For instance, for the SW estimator with 3 factors, the $\bar{R}^{2}$ using Romer's pre-1929 GDP data is 0.83 as opposed to 0.86 for the Balke and Gordon estimates.

${ }^{13}$ Interestingly, the very high amplitude of the World War II cycle in the Balke and Gordon estimates is not shared by an earlier (and previously widely used) indicator of U.S. GDP by Kuznets (1961). In fact, the Kuznets index (not shown to avoid cluttering but available from the authors upon request) and our index show a positive output gap of around 15 percent in 1944 as opposed to nearly 25 percent in the Balke and Gordon index. 
cyclical turning points in country indices with major global economic events is broadly corroborated for Brazil, Chile, and Mexico. ${ }^{14}$

In addition, the portrait of history provided by our index is consistent with narrative evidence about the macroeconomic repercussions of key country-specific events. In the case of Brazil, the index picks up the mini downturn associated with the 1888 political unrest (end of slavery and the republican transition) as well as the subsequent boom (the "Encilhamento") stemming from a liberal monetary reform that brought about an unprecedented boom in domestic credit and asset valuations in 1889-90 (see Trinner, 2000). The Brazil index tracks equally well what is deemed to have been one of Brazil's most protracted recessions which culminated in the country's first sovereign default and the debt rescheduling arrangements under the auspices of the Rothchilds in 1898 (see Fritsch, 1988). ${ }^{15}$ As for Chile, our index highlights the upturn of 1879-82 associated with the "War of the Pacific" (against Peru), the downturn around the country's exit from the gold standard in 1898 (Llona Rodriguez, 2000), as well as the severity of the 1929-32 depression in Chile due to plummeting terms of trade (Diaz-Alejandro, 1984). Both in Argentina and Chile as well as (to a lesser extent) Brazil, the index identifies clear turning points around the military coups of the 1960s and 1970s.

Finally, the Mexico index yields a picture of economic fluctuations that is remarkably consistent with that depicted by Mexican historiography starting with the 1879-82 upturn that is typically associated with the onset of the new regime headed by General Porfirio Diaz (Cardenas, 1997). Likewise, the subsequent recession, which takes place in the wake of the U.S. economic slowdown of 1883-84, is clearly depicted; its 1885 trough coincides with the well-documented austerity plan imposed by Diaz's finance minister Manuel Dublan that involved a temporary suspension of payments on domestic public debt (Marichal, 2002). This was followed by an upswing associated with Mexico's renewed access to international capital markets in the wake of the 1886-87 external debt settlement, which was later brought to a halt by a sharp worldwide fall in silver prices (Mexico's main export item) coupled with a severe downturn in the United States and sudden stop in capital flows to emerging markets in the early 1890s (c.f. Catão and Solomou, 2005). Finally, our business cycle index also provides a new measure of the severity of the economic downturn associated with the Mexican Revolution of 1911-20 identifying a trough around 1915-16-these were the years when the revolutionary conflict peaked and chaotic monetary conditions triggered a hyperinflation (Cardenas and Manns, 1987).

${ }^{14}$ In contrast with Argentina, Brazil and Chile were little affected by the 1994-95 Mexican crisis partly due to offsetting domestic developments. In the case of Brazil, a successful stabilization plan in 1994 and renewed political stability set off a domestic demand boom in the following year. In the case of Chile, stronger trade linkages with Asia, low public debt, and a significant improvement in external terms of trade limited the disruptive effects of the Tequila crisis on the domestic economy (see Singh et al., 2005).

${ }^{15}$ Unlike several Latin American countries which defaulted on their external debts (and some also on their domestic debts) more than once throughout the 19th century, Brazil consistently serviced its sovereign debt obligations until this time. 


\section{Stylized Business CyCle FACTS}

Armed with the business cycle indicators for the four countries, we turn to the task of establishing some stylized facts about the four countries' business cycles. We start with dating the respective turning points. A classic device to this end, which is also consistent with our definition of the business cycle as output deviations from a stochastic or deterministic trend, is the Bry and Boscham (1971) algorithm. ${ }^{16}$ It consists of a sequence of procedures starting with the search for extreme values in order to eliminate (near-) permanent jumps in the series associated with outliers, followed by the use of centered moving averages and the search for local maxima or minima within a chosen window length. ${ }^{17}$ To permit the identification of both shorter and longer cycles, Panels A and B of Table 4 report results based on two-year and six-year windows, respectively. As expected, the algorithm identifies peaks and troughs that are broadly consistent with a visual inspection of Figure 7 . When the narrow window is used, the average duration of the cycle is shorter overall, more so during the post-war era. This finding is consistent with evidence of the shortening business cycle length among advanced countries (see, e.g., Gordon, 1986). Using a longer window, Panel B indicates that the pre-cycle is dominated by the Kuznets or long swings, with similar turning points as those identified in the literature on Anglo-saxon economies (Solomou, 1987). This evidence is further reinforced by spectral density function estimates of the individual country indices, which point to a dominant cyclical length around 14 to 16 years during the 1870-1930 period (a typical Kuznets-swing length), followed by a 10-12 year cycle in post-war data (Table 5).

In sum, both the Bry and Bosham algorithm and the spectral density function estimates point to a reasonably long average cyclical duration in all four countries. The dominant cyclical pattern was generally longer in the pre-1930 era, but even in the post-World War II period, cycles in Latin America were substantially more protracted than in the United States and other advanced countries.

Against this background, Tables 6 and 7 report a set of descriptive statistics that help characterize other stylized facts about Latin America's business cycles from a broad crosscountry historical perspective. First, standard deviations corroborate the perception that Latin America has been a more cyclically volatile region than both countries deemed advanced by today's definition as well as countries such as Australia, Canada and Japan that were considered "emerging economies" in the pre-war world. This volatility gap between the two

${ }^{16}$ An alternative dating procedure which also builds on the Bry and Boschan approach has been advanced by Harding and Pagan (2002). Their procedure has been designed for use with level data, rather than with measures of the output gap. Marcellino (2005) discusses specifics of the two approaches. As in this paper, most of the recent empirical literature on business cycle identification and measurement has focused on the cycle defined in terms of deviations from trend (stochastic or deterministic).

${ }^{17}$ See King and Plosser (1989) and Watson (1994) for further details and application to U.S. data, for which the algorithm closely replicates the dating by the NBER's panel of experts. 
groups has changed over time, however. The four Latin American countries were clearly far more volatile in the early globalization period before the 1930 s-characterized as it was by free capital mobility and very limited quantitative restrictions on trade. Conversely, there is evidence that the inward growth policies did succeed in fending these countries off global instability in the 1930-70 sub-period, when global volatility generally rose, partly due to the recovery from the 1929-32 depression and war shocks. This appears reflected in the higher standard deviation of the output gap among advanced countries during the period as well as among a group of other developing economies for which pre-war GDP estimates are available (India, Indonesia, Korea, Malaysia, Sri Lanka, South Africa, Taiwan Province of China, and Turkey). But as output gap volatility came down in advanced countries in the post-1960s period (notwithstanding two oil shocks and dramatic changes in policy regimes), cyclical volatility in Latin America remained relatively high; only in the post-debt crisis period has Latin American cyclical volatility declined markedly compared to earlier levels. Further, Table 7 shows that this decline in cyclical volatility over the past 15 years or so has not been a preserve of Latin America but is also observed in other regions of the developing world-partly reflecting lower real interest rate and output volatility in the United States and other advanced countries (see Table 8). Yet, despite being low relative to its earlier historical record, business cycle volatility in Latin America still remains higher than in advanced countries as well as relative to Asian developing countries. Rolling standard deviations of the output gap in Figure 8 summarize this broad overview of volatility trends in the region by plotting both individual country trends as well as that of the common regional cycle (extracted as discussed below).

Table 8 focuses on key drivers of aggregate business cycles in the four economies, once again broken down by sub-periods. The table clearly highlights some stylized facts that have been stressed in previous studies (Backus and Kehoe, 1992; Mendoza, 1995; Basu and Taylor, 1999; Agénor et al. 2000). First, cyclical volatility in fixed investment is much higher than that of output. Second, and consistent with the findings of Backus and Kehoe (1992) for advanced countries, government spending volatility is higher than output volatility. For all four countries and across all sub-periods, the magnitude of two simple gauges of government-induced volatility - the real government expenditure cycle and the ratio of public expenditure to revenues - is staggering. Coupled with the positive loadings of the real government expenditure variable on the first (pro-cyclical) factor in Table 1-and with all the caveats about some inevitable endogeneity of this or indeed of any measure of the fiscal stance - this provides a prima facie case that changes in fiscal stances have been important drivers of the business cycle in these countries. This finding squares well with the post-1960 evidence on strong fiscal procyclicality in these countries provided in Kaminsky, Reinhart and Végh (2004) who use the cyclical component of real government spending as their main gauge.

Third, the volatility of monetary aggregates (expressed in real terms) is smaller than that of the fiscal variables with the exception of Argentina and Brazil over the past two decades and Chile in the 1970s reflecting bouts of high- and hyper-inflation in these countries.

Interestingly, however, inflation has been broadly counter-cyclical (see Table 1), in stark contrast with the Phillips-curve trade-off which is usually deemed to hold at least among advanced countries. The counter-cyclical behavior of inflation makes the apparent procyclicality of real wages (see Table 1) consistent both with models based on short-run 
nominal wage stickiness as well as with real business cycle models which emphasize the dominant role of technology shocks in shifting the labor demand schedule over business cycle frequencies. Finally, terms of trade fluctuations are highly procyclical and, consistent with earlier work (Mendoza, 1995), emerge as an important (and more clearly exogenous) source of output volatility. While this may not be particularly surprising given that all four countries have mainly been primary commodity exporters for much of the period (the manufacturing share of Brazil's and Mexico's exports only became prominent over the past couple of decades), it is still instructive to observe the sheer magnitude of the phenomenon. To the extent that terms of trade volatility has important welfare implications and is usually associated with poorer long-term growth performance (Blattman, Hwang, and Williamson, 2006), this emerges as an important feature of the data.

A final set of stylized facts that we document can be gleaned from a look at Figure 7, which shows that several major business cycle turning points-such as those of the early 1890s, World War I, the early 1930s and the early 1980s-are common to all or most of the four countries. A formal measure of such synchronicity is the concordance index proposed by Harding and Pagan (2002). It consists of a non-parametric measure of the relative frequency at which countries are jointly undergoing an expansion or a contraction phase gauged by a binary indicator. Table 9 reports the respective statistic which ranges from a minimum of zero (no concordance) to unity (perfect concordance). The results indicate that Latin American business cycles have displayed a reasonably high degree of synchronization through the 1870-2004 period. This is especially striking in light of the fact that there has been very little intra-regional trade between these economies until the past fifteen years or so, and that such synchronization did not decline dramatically during the period from the early 1930 s to the early 1970 s marked by strong trade restrictions and capital controls. These results indicate the presence of a common regional factor superimposed on the distinct country-specific business cycle drivers. To gauge this hypothesis more formally we use the econometric methodology from Section II to extract common factors from a pooled data set that brings all four countries' data together. ${ }^{18}$ The resulting regional factor jointly loads on the various country specific business cycle indicators. Corroborating the concordance metric of Table 9, the regional factor generates correlation coefficients between 0.6 and 0.75 with the procyclical factor $(\mathrm{F} 1)$ of the business cycle indices in the four individual countries. ${ }^{19}$ This clearly points to a sizeable regional common component. This is consistent with both the importance of external variables in the various countries' individual factor loadings (see Table 1), as well as with a long and distinguished literature on the roles of foreign interest rates, income shocks in advanced countries, and commodity terms of trade in triggering financial crises and, more generally, driving key macroeconomic aggregates in Latin

\footnotetext{
${ }^{18}$ The results are essentially the same, irrespective of whether we exclude or include the foreign interest rate and advanced countries' GDP in the panel. The results reported exclude the two external variables, if anything thus stacking the deck against finding sizeable comovement.

19 The respective plots and sub-period descriptive statistics are not reported to conserve on space but are available from the authors upon request.
} 
America (Diaz-Alejandro, 1984; Fishlow, 1989; Calvo, Leiderman, and Reinhart, 1993; Fernandez-Arias, 1994; Neumeyer and Perri, 2005).

\section{Conclusions}

This paper has sought to fill some of the lacuna in the international business cycle literature. Taking a century long view of the Latin American business cycle allowed us to characterize a host of stylized facts, compare them with existing evidence for other countries, and identify important differences in business cycle behavior across distinct policy and developmental regimes.

We have shown that Latin America has historically displayed high cyclical volatility compared to advanced country and other relevant benchmarks. Further, this volatility has been time-varying. It was highest during the early globalization era of the late 19th and early 20th century - precisely during the formative years of key national institutions- then declined markedly over the four decades since the great depression. Yet, we have also shown that after bouncing back in the wake of the large global shocks of the 1970s and early 1980s (Bretton Woods abandonment, oil price and interest rate shocks), business cycle volatility in Latin America subsequently declined to near historical lows. Since this coincides with greater trade and financial openness, a prima-facie link between business cycle volatility and openness is unwarranted looking at the period as a whole. Lower external volatility in output and interest rates over the past fifteen years or so is certainly a set of factors at play; more stable fiscal and monetary policies is another, which also helps explain the different volatility performances across countries amidst the general downward trend.

The paper's other main finding is that such volatility has been strikingly coupled with high business cycle persistence. Since the welfare costs of business cycles are known to rise on both volatility and persistence, the attendant welfare losses have been non-trivial. While it is beyond the scope of our analysis to probe further into the sources of output persistence in the four countries, there is cross-country evidence suggesting that the role of domestic institutions and their constraints on policy making are key (Acemoglu, Johnson, and Robinson, 2006). In addition, to the extent that external developments have themselves been a main source of such persistent shocks via commodity terms of trade and macroeconomic conditions in advanced countries, this has made the task of stabilization policies all the more difficult throughout the region.

We have also shown that several empirical regularities highlighted in the existing business cycle literature readily apply to the four countries. One set of regularities pertains to the countercyclicality of trade balances and the much higher cyclical amplitude of both fixed investment and real government spending relative to output. Indeed, using the simple yardstick of the co-movement between real government expenditures and the output cycle employed elsewhere (Kaminsky, Reinhart and Végh, 2004), we find that fiscal policy has been procylical in all four countries. A comparison between the volatility of external aggregates such as the output gap in advanced countries and external interest rates, and the volatility of domestic aggregates such as public expenditures and revenues as well as, to a lesser extent, real money indicate, if anything, that domestic amplification mechanisms have 
played a key role. This suggest that these mechanisms deserves close scrutiny by future research on business cycles in these countries.

Finally, our common factor framework also allowed us to identify a sizeable regional common component in Latin American business cycles. Since trade linkages between these economies have been small well into the 1980s, and as capital market linkages remain so to date, this highlights the role of global factors in driving such a regional common cycle. This evidence is consistent with a long literature on the roles of external factors in both triggering financial crises (e.g. Diaz-Alejandro, 1984; Fishlow, 1989) and driving key macroeconomic aggregates in the region (Calvo, Leiderman and Reinhart, 1993; Fernandez-Arias, 1994; Neumeyer and Perri, 2005), as well as with the findings of more general and recent studies emphasizing the role of international factors in individual countries' business cycles (Kose, Otrok, Whiteman, 2003; Canova 2004). In extending these findings to Latin America based on wider time series evidence, the results presented in this paper further highlight the limited scope that regional risk-sharing has had historically. 


\section{REFERENCES}

Acemoglu Daron, Simon Johnson, James Robinson and Yunyong Thaicharoe, 2003, "Institutional Causes, Macroeconomic Symptoms: Volatility, Crises and Growth," Journal of Monetary Economics, Vol. 50, pp. 49-123.

Acemoglu Daron, Simon Johnson and James Robinson, 2006, "Institutions as the Fundamental Cause of Long-Run Growth," ed. by Philippe Aghion and Steven Durlauf, Handbook of Economic Growth, Forthcoming.

Agénor, Pierre-Richard, John McDermott, and Eswar S Prasad., 2000, "Macroeconomic Fluctuations in Developing Countries: Some Stylized Facts," World Bank Review, No. 14 (2), pp. 251-86.

Artis, Michael, Zenon G. Kontolemis, and Denise Osborn, 1997, "Business Cycles for G7 and European Countries," Journal of Business, Vol. 70, No. 2, pp. 249-79.

Backus, David, and Patrick Kehoe, 1992, "International Evidence on the Historical Properties of Business Cycles," American Economic Review, Vol. 82, pp. 864-88.

Balke, Nathan, and Robert Gordon, 1989, “The Estimation of Prewar Gross National Product: Methodology and New Evidence," Journal of Political Economy, Vol. 97, No. 1, pp. 38-92.

Banco Central de la Republica Argentina, 1976, "Cuentas Nacionales de la Republica Argentina," Buenos Aires.

Basu, Susanto, and Alan M. Taylor, 1999, "Business Cycles in International Historical Perspective," Journal of Economic Perspectives, Vol. 13, No. 2, pp. 45-68.

Baxter, Marianne, and Robert G. King, 1999, "Measuring Business Cycles: Approximate Band-Pass Filters for Economic Time Series," Review of Economics and Statistics, Vol. 81, No. 4, pp. 575-59.

Bernanke Ben, Boivin Jean; Eliasz Piotr S., 2005, "Measuring the Effects of Monetary Policy: A Factor-Augmented Vector Autoregressive (FAVAR) Approach, Quarterly Journal of Economics, Vol. 120, No. 1, pp. 387-422.

Blattman, Chris, Jason Hwang, and Jeffrey Williamson, 2006, The Impact of the Terms of Trade on Economic Development in the Periphery, 1870-1939: Volatility and Secular Change," Journal of Development Economics, Forthcoming.

Boivin, Jearn, and Serena Ng, 2003, "Are More Data Always Better for Factor Analysis?" NBER Working Paper No. 9829 (Cambridge, Massachusetts: National Bureau of Economic Research). 
Braun, Juan, Matías Braun, Ignacio Briones, José Diaz, Rolf Luders, and Gert Wagner, 2000, "Economía Chilena 1810-1995: Estadísticas Históricas," Working Paper 187, Catholic University of Chile, Instituto de Economía.

Bry, Gerard, and Boschan, Charlotte, 1971, Cyclical Analysis of Time Series: Selected Procedures and Computer Programs (New York: Columbia University Press).

Burns, Arthur F., and Wesley C. Mitchell, 1946, Measuring Business Cycles (New York, New York: National Bureau of Economic Research).

Calvo, Guillermo, Leonardo Leiderman, and Carmen Reinhart, 1993, "Capital Flows and Real Exchange Rate Appreciations in Latin America," IMF Staff Papers, No. 40, (1), pp. 108-151.

Canova, Fabio, 2005, “The Transmission of US Shocks to Latin America," Journal of Applied Econometrics, Vol. 10, pp. 229-251.

Cárdenas, Enrique, 1997, "A Macroeconomic Interpretation of Nineteenth-Century Mexico," in How Latin America Fell Behind: Essays on the Economic History of Brazil and Mexico, ed. by S. Haber (Stanford, CA).

Cárdenas, Enrique, and Carlos Manns, 1987, "Inflation and Monetary Stabilization in Mexico During the Revolution," Journal of Development Economics, Vol. 27, pp. 275-94.

Catão, Luis, and Solomos Solomou, 2005, "Effective Exchange Rates and the Classical Gold Standard Adjustment," American Economic Review, Vol. 94, pp. 1259-75.

Contador, Claudio, and Claudio Haddad, 1975, "Produto Real, Moeda and Preços: A Experiência Brasileira No. Período 1861-1970,” Revista Brasileira de Estatistica, Jul./Set., pp. 407-440.

D'Agostino, Antonello, and Domenico Giannone, 2004, "Comparing Alternative Predictors Based on Large Panels Factor Models" (unpublished).

della Paolera, Gerardo, 1989, "How the Argentine Economy Performed During the International Gold Standard: A Re-Examination, PhD Dissertation," University of Chicago.

della Paolera, Gerardo, and Alan Taylor, 2003, A New Economic History of Argentina (New York: Cambridge University Press).

Diaz-Alejandro, Carlos F., 1984, "Latin America in the 1930s: The Role of the Periphery in World Crisis," in Latin America in the 1930s, ed. by Rosemary Thorp (New York: St. Martin's Press).

Engle, Robert, F. and João V. Issler, 1993, "Common Trends and Common Cycles in Latin America,” Revista Brasileira de Economia, No. 47, 2, pp. 149-76. 
Fernandez-Arias, Eduardo, 1994, "The New Wave of Private Capital Inflows: Push or Pull?" Journal of Development Economics, No. 48, pp. 389-418.

Fishlow, Albert, 1989, "Conditionality and Willingness to Pay: Some Parallels from the 1890s," in The International Debt Crisis in Historical Perspective, ed. by Barry Eichengreen and Peter H. Lindert (Cambridge, Massachusetts: MIT Press).

Forni, M., M. Hallin, M. Lippi, and L. Reichlin, 2000, “The Generalized Factor Model: Identification and Estimation," Review of Economics and Statistics, Vol. 82, pp. 40-554. , 2003, “The Generalized Dynamic Factor Model: Forecasting and One Sided Estimation," CEPR Working Paper No. 3432 (London: Centre for Economic Policy Research).

Fritsch, Winston, 1988, External Constraints on Economic Policy in Brazil, 1889-1930, (London: Macmillan).

Giannone, D., L. Reichlin, and L. Sala, 2004, "Monetary Policy in Real Time," NBER Macroeconomics Annual.

Goldsmith, Raymond, 1986, Brasil: 1850-1984: Desenvolvimento Financeiro Sob Um Século de Inflação, (São Paulo: Harper and Row do Brasil).

Gordon, Robert, 1986, The American Business Cycle: Continuity and Change (Chicago: University of Chicago Press).

Haddad, Claudio, 1978, O Crescimento do Produto Real Brasileiro, 1900-47 (Rio de Janeiro: Brasil).

Harding, Don, and Adrian Pagan, 2002, "Dissecting the Cycle: A Methodological Investigation,” Journal of Monetary Economics, No. 49 (2), pp. 365-81.

Hoffmaister, Alexander, and Jorge Roldos, 1997, “Are Business Cycles Different in Asia and Latin America?” IMF Working Paper No. 97/9 (Washington: International Monetary Fund).

Kaminsky, Graciela, Carmen Reinhart, and Carlos Végh, 2004, "When It Rains, It Pours: Procyclical Capital Flows and Macroeconomic Policies," NBER Working Paper No. 10780 (Cambridge, Massachusetts: National Bureau of Economic Research).

King, Robert, and Charles I. Plosser, 1994, "Real Business Cycles and the Test of the Adelmans," Journal of Monetary Economics, No. 33, pp. 405-38.

Kose, Ayhan, and Raymond Reizman, 2001, "Trade Shocks and Macroeconomic Fluctuations in Africa," Journal of Development Economics, Vol. 65, pp. 55-80. 
Kose, A., Otrok, C., Whiteman, 2003, "International Business Cycles: World, Region, and Country Specific Factors,” American Economic Review, Vol. 93, pp. 1216-1239.

Kose, A., E. Prasad, and M. Terrones, 2006, "How Do Trade and Financial Integration Affect the Relationship Between Growth and Volatility," Journal of International Economics, Forthcoming.

Kuznets, Simon, 1958, "Long Swings in the Growth of Population and in Related Economic Variables," Proceedings of the American Philosophical Society, Vol. 102, pp. 25-52. , 1961, Capital in the American Economy, Its Formation and Financing (Princeton, New Jersey: Princeton University Press).

Kydland, Finn, and Carlos E.J. Zarazaga, 1997, "Is the Business Cycle of Argentina "Different"? Economic Review (Federal Reserve Bank of Dallas, Fourth quarter) pp.21-36.

Llona-Rodriguez, Agustin, 2000, "Chile During the Gold Standard: A Successful Paper Money Experience," in Monetary Standards in the Periphery. Paper, Silver and Gold 1854-1913, ed. by Aceña, P.M. and Jaime Reis, (London: MacMillan).

Maddison, Angus, 1995, Monitoring the World Economy, OECD, Paris. , 2003, The World Economy: Historical Statistics, OECD, Paris.

Marcellino, Massimiliano, 2006, “Leading Indicators: What Have We Learned?” in Handbook of Economic Forecasting ed. by Graham Elliott, Clive Granger and Allan Timmermann, (Amsterdam: North-Holland), Forthcoming.

Marichal, Carlos, 2002, "The Construction of Credibility: Financial Market Reform and the Renegotiation of Mexico's External Debt in the 1880s," in The Mexican Economy, 1870-1930, ed. by Bortz, Jeffrey and Stephen Haber (Stanford, California: Stanford University Press), pp. 93-119.

Mendoza, Enrique, 1995, “The Terms of Trade, the Real Exchange Rate, and Economic Fluctuations," International Economic Review, No. 36, pp. 101-37.

Mitchell, Brian, 2003, International Historical Statistics: The Americas (New York: Palgrave Macmillan).

Moore, Geoffrey H., 1983, Business Cycle, Inflation, and Forecasting (Cambridge, Massachusetts: Ballinger Publishing Company).

Neumeyer, Pablo and Fabrizio Perri, 2005, "Business Cycles in Emerging Economies: The Role of Interest Rates," Journal of Monetary Economics, Vol. 52, pp. 345-80. 
Pallage, Stephane and Michael Robe, 2003, "On the Welfare Cost of Economic Fluctuations in Developing Countries," International Economic Review, Vol. 44, No. 2, pp. 677-98.

Romer, Christina, 1989, “The Prewar Business Cycle Reconsidered: New Estimates of Gross National Product, 1969-1918," Journal of Political Economy, Vol. 97, No. 1, pp. 1-37.

Rostow, W.W., 1980, Why the Poor Get Richer and the Richer Slow Down: Essays in the Marshallian Long Period, (London: MacMillan).

Sheffrin, Steven, 1988, "Have Economic Fluctuations Been Dampened? A Look at Evidence Outside the United States," Journal of Monetary Economics, Vol. 21, pp. 73-83.

Singh, Anoop, Agnes Belaish, Charles Collyns, Paula De Masi, Reva Krieger, Guy Meredith, and Robert Rennhack, 2005, Stabilization and Reform in Latin America IMF Occasional Paper No. 238 (Washington: International Monetary Fund).

Solomou, Solomos, 1987, Phases of Economic Growth, 1850-1973: Kondratieff Waves and Kuznets Swings, (Cambridge: Cambridge University Press).

Stock, James H., and Mark W. Watson, 1989, "New Indexes of Coincident and Leading Economic Indicators," NBER Macroeconomics Annual, pp. 351-93.

— , 1991, "A Probability Model of the Coincident Economic Indicator," in Leading Economic Indicators: New Approaches and Forecasting Records, ed. by Kajal Lahiri, and Geoffrey H. Moore (Cambridge: Cambridge University Press).

— 1999, "Business Cycle Fluctuations in U.S. Macroeconomic Time Series," in Handbook of Macroeconomics, ed. by John Taylor and Michael Woodford, (Amsterdam: North Holland).

_ 2002, "Macroeconomic Forecasting Using Diffusion Indexes," Journal of Business and Economic Statistics, Vol. 20, pp. 147-162.

— 2005, "Forecasting with Many Predictors," in Handbook of Economic Forecasting ed. by Graham Elliott, Clive Granger and Allan Timmermann (Amsterdam: North-Holland).

Triner, Gail D., 2000, Banking and Economic Development: Brazil, 1889-1930, (New York: Palgrave).

Van Wincoop, Eric, 1999, "How Big Are the Potential Gains from International Risk Sharing?" Journal of International Economics, Vol. 47, No. 1, pp. 109-135.

Watson, Mark W., 1994, "Business-Cycle Durations and Postwar Stabilization of the U.S. Economy," American Economic Review, Vol. 84, No. 1, pp. 24-46. 
Table 1: Factor Loadings

The table reports the eigenvectors associated with the first two common factors constructed from the data sample covering the period $1870-2004$.

\begin{tabular}{lcccccccc}
\hline & \multicolumn{1}{c}{ Argentina } & \multicolumn{2}{c}{ Brazil } & \multicolumn{2}{c}{ Chile } & \multicolumn{2}{c}{ Mexico } \\
\hline & F1 & F2 & F1 & F2 & F1 & F2 & F1 & F2 \\
\hline Agriculture & - & - & - & - & 0.03 & -0.21 & 0.25 & -0.22 \\
Communication & - & - & 0.29 & -0.11 & - & - & - & - \\
Manufacturing & - & - & - & - & 0.22 & 0.29 & 0.19 & 0.21 \\
Mining & - & - & - & - & 0.35 & -0.16 & 0.26 & 0.05 \\
Cemeut & 0.30 & -0.06 & 0.34 & -0.07 & - & - & 0.21 & 0.24 \\
Transportation & 0.35 & -0.05 & 0.21 & -0.26 & - & - & 0.26 & -0.05 \\
Fixed Investmeut & 0.37 & -0.09 & 0.42 & 0.02 & 0.34 & -0.03 & 0.30 & 0.30 \\
Govt. Expenditures & 0.30 & 0.31 & 0.21 & 0.36 & 0.30 & 0.08 & 0.24 & -0.26 \\
Govt. Revenues & 0.31 & -0.04 & 0.31 & 0.22 & 0.34 & -0.03 & 0.27 & -0.16 \\
Narrow Money & 0.19 & 0.39 & 0.11 & 0.18 & 0.11 & 0.45 & 0.34 & -0.13 \\
Broad Mouey & 0.30 & 0.16 & 0.05 & 0.18 & 0.18 & 0.42 & 0.33 & -0.14 \\
Inflation & -0.08 & 0.30 & -0.10 & -0.04 & -0.07 & 0.03 & -0.18 & -0.03 \\
Domestic Interest Rate & -0.05 & -0.37 & -0.07 & -0.02 & -0.00 & -0.33 & - & - \\
Mortgage Credit & - & - & - & - & 0.05 & -0.20 & - & - \\
Terms of Trade & 0.17 & 0.09 & 0.27 & -0.31 & 0.19 & 0.06 & 0.09 & 0.28 \\
Real Exchange Rate & 0.00 & -0.43 & 0.20 & -0.19 & 0.10 & -0.43 & 0.14 & 0.43 \\
Export Volume & 0.04 & -0.11 & -0.05 & 0.17 & 0.31 & -0.25 & 0.21 & -0.12 \\
Import Volume & 0.36 & -0.26 & 0.43 & -0.06 & 0.39 & 0.01 & 0.28 & 0.38 \\
Trade Balance & -0.25 & 0.24 & -0.30 & -0.11 & -0.06 & -0.16 & -0.08 & -0.22 \\
External Spread & - & - & 0.03 & 0.27 & - & - & - & - \\
Foreign Capital Inflows & 0.23 & -0.17 & - & - & - & - & - & - \\
Foreign 3m-Tbill & 0.08 & -0.11 & 0.08 & 0.10 & -0.06 & 0.13 & 0.17 & -0.25 \\
Foreign Output & -0.01 & 0.11 & 0.02 & -0.43 & 0.26 & -0.00 & 0.09 & 0.16 \\
Real wage & 0.20 & 0.25 & 0.02 & 0.40 & 0.29 & -0.06 & 0.25 & -0.24 \\
Populatiou & 0.09 & 0.20 & -0.10 & -0.27 & 0.01 & 0.12 & 0.00 & -0.10 \\
\hline
\end{tabular}




\section{Table 2: In-Sample Fit}

The table reports the adjusted R-squared for the backcasting equation estimated over the post-war sample (19502004). Panel A reports results wheu the factors are extracted from a panel spanning the period 1870-2004 (1878-2004 for Mexico), while iu panel $B$ the factors are extracted from a larger cross-section of variables evailable during the sample 1900-2004. All-regressors reports results from the backcasting equation that includes all available variables. The remaining backcasting equations estimate the factors using either the Stock and Watson (2002) approach with I static factors (SW(r)) or the Forni et al (2000) dynamic factor approach with $\mathrm{q}$, $\mathrm{r}$ dynamic and static factors, respectively (FHLR $(\mathrm{q}, \mathrm{r}))$.

Panel A: 1870-2004

\begin{tabular}{lcccc}
\hline & Argentina & Brazil & Chile & Mexico \\
\hline All regressors & 0.89 & 0.77 & 0.91 & 0.92 \\
SW(1) & 0.76 & 0.51 & 0.72 & 0.83 \\
SW(2) & 0.81 & 0.52 & 0.74 & 0.83 \\
SW(3) & 0.81 & 0.69 & 0.75 & 0.86 \\
SW(4) & 0.82 & 0.71 & 0.78 & 0.87 \\
FHLR(1,1) & 0.79 & 0.47 & 0.71 & 0.75 \\
FHLR(1,2) & 0.82 & 0.67 & 0.71 & 0.76 \\
FHLR(1,3) & 0.81 & 0.68 & 0.71 & 0.87 \\
FHLR(1,4) & 0.81 & 0.67 & 0.80 & 0.86 \\
FHLR(2,1) & 0.80 & 0.46 & 0.67 & 0.77 \\
FHLR(2,2) & 0.81 & 0.54 & 0.74 & 0.76 \\
FHLR(2,3) & 0.80 & 0.56 & 0.74 & 0.84 \\
FHLR(2;4) & 0.80 & 0.68 & 0.80 & 0.85 \\
\hline
\end{tabular}

Panel B: 1900-2004

\begin{tabular}{lcccc}
\hline & Argentina & Brazil & Chile & Mexico \\
\hline All regressors & 0.94 & 0.90 & 0.91 & 0.92 \\
SW(1) & 0.84 & 0.65 & 0.72 & 0.83 \\
SW(2) & 0.88 & 0.65 & 0.74 & 0.83 \\
SW(3) & 0.88 & 0.83 & 0.75 & 0.86 \\
SW(4) & 0.88 & 0.84 & 0.78 & 0.87 \\
FHLR(1,1) & 0.85 & 0.61 & 0.71 & 0.75 \\
FHLR(1,2) & 0.87 & 0.79 & 0.71 & 0.76 \\
FILR(1,3) & 0.88 & 0.80 & 0.71 & 0.87 \\
FHLR $(1,4)$ & 0.88 & 0.80 & 0.80 & 0.86 \\
FHLR(2,1) & 0.86 & 0.60 & 0.67 & 0.77 \\
FHLR(2,2) & 0.88 & 0.66 & 0.74 & 0.76 \\
FHLR(2,3) & 0.88 & 0.70 & 0.74 & 0.84 \\
FHLR(2,4) & 0.88 & 0.81 & 0.80 & 0.85 \\
\hline
\end{tabular}


Table 3: In-sample and Out-of-sample Fit for the USA

The table reports the adjusted R-squared for the backcasting equation estimated over the post-war sample (14502004) and the pre-war period (1870-1949) with US data. The factors are extracted from a panel spanning the period 1870-2004. For the post-war sample we report the results using the Balke and Gordon series while for the pre-war period we report results obtained by using the Balke-Gordon, Romer, and Kuznets estimates.

\begin{tabular}{lcccc}
\hline & 1950-2004 & \multicolumn{3}{c}{$1870-1949$} \\
\hline & Balke-Gordon & Balke-Gordon & Romer & Kuznets \\
\hline All regressors & 0.962 & 0.893 & 0.894 & 0.811 \\
SW(1) & 0.762 & 0.725 & 0.681 & 0.675 \\
SW(2) & 0.758 & 0.725 & 0.677 & 0.730 \\
SW(3) & 0.794 & 0.863 & 0.832 & 0.807 \\
SW (4) & 0.800 & 0.874 & 0.866 & 0.805 \\
FHLR(1,1) & 0.761 & 0.763 & 0.716 & 0.601 \\
FHLR(1,2) & 0.761 & 0.764 & 0.723 & 0.723 \\
FHLR(1,3) & 0.803 & 0.847 & 0.823 & 0.740 \\
FHLR(1,4) & 0.802 & 0.846 & 0.822 & 0.737 \\
FHLR(2,1) & 0.816 & 0.802 & 0.766 & 0.727 \\
FHLR (2,2) & 0.813 & 0.809 & 0.767 & 0.766 \\
FHLR $(2,3)$ & 0.809 & 0.834 & 0.804 & 0.764 \\
FHLR(2,4) & 0.819 & 0.887 & 0.868 & 0.790 \\
\hline
\end{tabular}


Table 4: Dating the Cycle

The table reports peak and trough dates selected by the Bry-Boschan algorithm. Results in Panel A impose a minimum of two years between peaks, while results in Panel B impose a minimum of six years between peaks.

Panel A

\begin{tabular}{llllllll}
\hline \multicolumn{2}{c}{ Argenting } & \multicolumn{3}{c}{ Brazil } & \multicolumn{2}{c}{ Chile } & \multicolumn{2}{c}{ Mexico } \\
\hline Peaks & Troughs & Peaks & Troughs & Peaks & Troughs & Peaks & Troughs \\
\hline 1873 & 1880 & 1872 & 1876 & 1875 & 1877 & 1883 & 1886 \\
1884 & 1887 & 1881 & 1886 & 1882 & 1885 & 1891 & 1894 \\
1889 & 1891 & 1891 & 1893 & 1890 & 1894 & 1898 & 1902 \\
1893 & 1895 & 1896 & 1901 & 1896 & 1897 & 1907 & 1909 \\
1899 & 1902 & 1907 & 1908 & 1898 & 1902 & 1912 & 1916 \\
1913 & 1918 & 1912 & 1915 & 1907 & 1909 & 1921 & 1927 \\
1923 & 1926 & 1927 & 1931 & 1912 & 1915 & 1928 & 1932 \\
1930 & 1933 & 1938 & 1942 & 1918 & 1919 & 1936 & 1938 \\
1938 & 1945 & 1946 & 1948 & 1926 & 1927 & 1941 & 1942 \\
1948 & 1953 & 1951 & 1956 & 1929 & 1932 & 1945 & 1947 \\
1958 & 1959 & 1962 & 1967 & 1937 & 1942 & .1951 & 1953 \\
1961 & 1963 & 1974 & 1976 & 1943 & 1947 & 1956 & 1959 \\
1965 & 1968 & 1979 & 1983 & 1952 & 1954 & 1960 & 1962 \\
1970 & 1971 & 1986 & 1988 & 1957 & 1958 & 1965 & 1971 \\
1974 & 1978 & 1990 & 1992 & 1962 & 1965 & 1974 & 1977 \\
1980 & 1985 & 1997 & 1999 & 1966 & 1970 & 1981 & 1988 \\
1987 & 1990 & 2002 & - & 1972 & 1975 & 1994 & 1995 \\
1994 & 1995 & - & - & 1980 & 1983 & 2000 & 2002 \\
1997 & 2002 & - & - & 1989 & 1990 & - & - \\
- & - & - & - & 1997 & 2002 & - & - \\
\hline
\end{tabular}

Panel B

\begin{tabular}{llllllll}
\hline \multicolumn{2}{c}{ Argentina } & \multicolumn{2}{c}{ Brazil } & \multicolumn{2}{c}{ Chile } & \multicolumn{2}{c}{ Mexico } \\
\hline Peaks & Troughs & Peaks & Troughs & Peaks & Troughs & Peaks & Troughs \\
\hline 1873 & 1880 & 1881 & 1876 & 1890 & 1885 & 1883 & 1886 \\
1889 & 1891 & 1891 & 1886 & 1912 & 1909 & 1898 & 1916 \\
1899 & 1902 & 1913 & 1901 & 1929 & 1919 & 1921 & 1927 \\
1913 & 1918 & 1927 & 1915 & 1943 & 1932 & 1936 & 1938 \\
1930 & 1933 & 1938 & 1931 & 1952 & 1947 & 1951 & 1959 \\
1948 & 1953 & 1951 & 1942 & 1980 & 1958 & 1965 & 1971 \\
1961 & 1971 & 1962 & 1956 & 1997 & 1983 & 1981 & 1995 \\
1980 & 1985 & 1979 & 1967 & - & - & - & - \\
1997 & & 1997 & 1992 & - & - & - & - \\
\hline
\end{tabular}


Table 5: Spectral Density Function Estimates of Cyclical Durations

The table reports business cycle durations (in years) for different sample periods. The estimates refer to the peak value of a Bartlett lag window estimate using a bandwidth set at twice the number of sample observations.

\begin{tabular}{ccccccc}
\hline & 1870-1929 & & $\mathbf{1 9 3 0 - 1 9 7 0}$ & \multicolumn{3}{c}{$\mathbf{1 9 7 1 - 2 0 0 4}$} \\
\hline \multirow{3}{*}{ Argentina } & Estimate & $\mathrm{T}$ & Estimate & $\mathrm{T}$ & Estimate & $\mathrm{T}$ \\
& 4.64 & 16 & 3.36 & 12 & 2.11 & 12 \\
Brazil & $(1.96)$ & & $(1.48)$ & & $(1.02)$ & \\
& 4.57 & 16 & 3.90 & 12 & 2.35 & 12 \\
Chile & $(1.92)$ & & $(1.72)$ & & $(1.13)$ & \\
& 2.18 & 16 & 2.05 & 12 & 3.79 & 8 \\
Mexico & $(0.92)$ & & $(0.90)$ & & $(1.90)$ & \\
& 3.75 & 14 & 2.35 & 8 & 3.14 & 12 \\
& $(1.59)$ & & $(1.04)$ & & $(1.52)$ & \\
\hline
\end{tabular}


Table 6: Persistence and Volatility of the Cycle

The table reports autocorrelation and standard deviation estimates of the cycle obtained from a static two-factor model. Panel A shows resnits for the backcasted data while Panel B reports results for actual business cycle measnres.

Panel A: Backcasted Data

\begin{tabular}{lcccccccc}
\hline \hline & \multicolumn{9}{c}{$1870-1929$} & & \multicolumn{4}{c}{$1930-1970$} & \\
\hline & Arg & Bra & Chi & Mex & Arg & Bra & Chi & Mex \\
AR(1) & 0.721 & 0.706 & 0.549 & 0.739 & 0.593 & 0.763 & 0.538 & 0.573 \\
Std & 0.065 & 0.048 & 0.063 & 0.066 & 0.046 & 0.032 & 0.078 & 0.029 \\
\hline \multicolumn{9}{c}{$1971-1987$} \\
\hline
\end{tabular}

Panel B: Actual Data

\begin{tabular}{lcccccccc}
\hline & \multicolumn{9}{c}{$1971-1987$} & \multicolumn{4}{c}{$1988-2004$} \\
\hline & Arg & Bra & Chi & Mex & Arg & Bra & Chi & Mex \\
AR(1) & 0.168 & 0.624 & 0.590 & 0.644 & 0.590 & 0.622 & 0.687 & 0.383 \\
Std & 0.031 & 0.043 & 0.081 & 0.039 & 0.068 & 0.021 & 0.033 & 0.030 \\
\hline
\end{tabular}




\section{Table 7: International Comparisons}

The table reports autocorrelation and standard deviation estimates of the business cycle. Panel A shows median regional values for Latin America, LA-4, (Argentina, Brazil, Chile and Mexico), European Countries, EU-4, (France, Germany, Italy and the UK), New World countries, NW-3, (USA, Canada and Australia) and Japan, JP. The estimates of the cycle for Latin America are obtained from a dynamic factor model. Panel B compares median regional values for Latin America, LA-4, (Argentina, Brazil, Chile and Mexico), other developing countries, Other LDCs, (India, Indonesia, Korea, Malaysia, Taiwan, South Africa, and Turkey), Africa (41 countries), Asia (11 countries), and the Middle East (18 countries) based on actual data.

Panel A: Advanced Countries Data

\begin{tabular}{lcccccccc}
\hline & \multicolumn{3}{c}{$1870-1929$} & \multicolumn{5}{c}{$1930-1970$} \\
\cline { 2 - 8 } AR(1) & LA-4 & EU-4 & NW-3 & JP & LA-4 & EU-4 & NW-3 & JP \\
\cline { 2 - 8 } Std & 0.719 & 0.507 & 0.517 & 0.031 & 0.583 & 0.698 & 0.731 & 0.599 \\
& 0.065 & 0.051 & 0.050 & 0.035 & 0.039 & 0.101 & 0.066 & 0.128 \\
\hline & \multicolumn{3}{c}{$1971-1987$} & \multicolumn{5}{c}{$1988-2004$} \\
LA-4 & EU-4 & NW-3 & JP & LA-4 & EU-4 & NW-3 & JP \\
\cline { 2 - 8 } AR(1) & 0.610 & 0.526 & 0.477 & 0.683 & 0.482 & 0.619 & 0.501 & 0.417 \\
Std & 0.038 & 0.017 & 0.021 & 0.027 & 0.022 & 0.015 & 0.022 & 0.018 \\
\hline
\end{tabular}

Panel B: Developing Countries Data

\begin{tabular}{|c|c|c|c|c|c|c|c|c|c|c|}
\hline \multirow{3}{*}{$\operatorname{AR}(1)$} & \multicolumn{5}{|c|}{$1930-1950$} & \multicolumn{5}{|c|}{$1950-1970$} \\
\hline & LA-4 & Other LDCs & Africa & Asia & Middle East & $\overline{\mathrm{LA}-4}$ & Other LDCs & Africa & Asia & Middle East \\
\hline & 0.560 & 0.617 & - & - & - & 0.273 & 0.051 & 0.502 & 0.416 & 0.402 \\
\hline Std & 0.040 & 0.078 & - & - & - & 0.031 & 0.030 & 0.038 & 0.028 & 0.043 \\
\hline & \multicolumn{5}{|c|}{$1971-1987$} & \multicolumn{5}{|c|}{$1988-2004$} \\
\hline & LA-4 & Other LDCs & Africa & Asia & Middle East & LA-4 & Other LDCs & Africa & Asia & Middle East \\
\hline $\operatorname{AR}(1)$ & 0.607 & 0.551 & 0.563 & 0.486 & 0.447 & 0.606 & 0.531 & 0.481 & 0.547 & 0.572 \\
\hline Std & 0.041 & 0.038 & 0.051 & 0.033 & 0.031 & 0.031 & 0.028 & 0.035 & 0.028 & 0.057 \\
\hline
\end{tabular}


Table 8: Cyclical Volatility Estimates of Selected Variables

The table reports standard deviations (in percent) for selected variables and different sample periods.

Panel A: 1870-1829

\begin{tabular}{lcccc}
\hline & Argentina & Brazil & Chile & Mexico \\
\hline Foreign Interest Rate & 5.34 & 5.34 & 5.34 & 5.34 \\
Foreign Output & 3.46 & 3.46 & 3.46 & 3.46 \\
Domestic Output & 6.49 & 4.84 & 6.25 & 7.29 \\
Terms of Trade & 14.99 & 21.79 & 33.05 & 29.00 \\
Export Volume & 13.20 & 10.21 & 17.61 & 10.34 \\
Fixed Investment & 107.80 & $\mathbf{3 7 . 1 6}$ & $\mathbf{7 6 . 0 5}$ & 79.00 \\
Government Spending & 66.23 & $\mathbf{4 7 . 8 5}$ & 39.33 & 33.71 \\
Expenditure/Revenue & 28.41 & 20.82 & 28.83 & 10.70 \\
Narrow Money & 14.94 & 15.32 & 16.64 & 35.07 \\
Broad Money & 14.82 & 14.62 & 11.39 & 35.83 \\
Real Wage & 12.33 & 9.14 & 8.69 & 32.73 \\
\hline
\end{tabular}

Panel B: 1930-1970

\begin{tabular}{lcccc}
\hline & Argentina & Brazil & Chile & Mexico \\
\hline Foreign Interest Rate & 4.68 & 4.68 & 4.68 & 4.68 \\
Foreign Output & 7.08 & 7.08 & 7.08 & 7.08 \\
Domestic Output & 4.56 & 3.25 & $\mathbf{7 . 6 9}$ & 2.90 \\
Terms of Trade & 12.20 & 20.27 & 26.66 & 29.37 \\
Export Volume & 13.59 & 9.95 & 16.89 & 9.52 \\
Fixed Investment & 67.96 & 29.56 & 64.60 & 102.36 \\
Government Spending & 14.09 & 13.27 & 13.69 & 16.73 \\
Expenditure/Revenue & 23.36 & 16.21 & 13.83 & 19.64 \\
Narrow Money & 10.20 & 11.01 & 19.90 & 15.43 \\
Broad Money & 12.33 & 10.84 & 13.46 & 13.62 \\
Real Wage & 6.99 & 6.54 & 13.07 & 18.22 \\
\hline
\end{tabular}

Panel C: 1971-2004

\begin{tabular}{lcccc}
\hline & Argentina & Brazil & Chile & Mexico \\
\hline Foreign Interest Rate & 2.20 & 2.20 & 2.20 & 2.20 \\
Foreign Output & 2.97 & 2.97 & 2.97 & 2.97 \\
Domestic Output & 5.01 & 2.94 & 5.35 & 3.30 \\
Terms of Trade & 27.14 & 12.24 & 16.45 & 22.20 \\
Export Volume & 12.94 & 8.11 & 6.87 & 9.61 \\
Fixed Investment & 16.39 & 15.82 & 16.10 & 14.93 \\
Government Spending & 8.14 & 66.37 & 44.21 & 40.33 \\
Expenditure/Revenue & 22.53 & 9.05 & 12.15 & 18.05 \\
Narrow Money & 16.84 & 15.81 & 21.89 & 10.48 \\
Broad Money & 20.32 & 22.82 & 17.31 & 19.00 \\
Real Wage & 12.44 & 5.72 & 12.30 & 15.13 \\
\hline
\end{tabular}


Table 9: Synchronization of the Latin American Cycles

The table reports the Harding-Pagan concordance statistic. Values close to one show evidence of a stronger degree of synchronicity.

\begin{tabular}{llllllllll}
\hline & \multicolumn{3}{c}{$1878-1929$} & \multicolumn{4}{c}{$1930-1970$} \\
\hline & Arg & Bra & Chi & Mex & Arg & Bra & Chi & Mex \\
Arg & 1.00 & 0.48 & 0.54 & 0.62 & 1.00 & 0.54 & 0.54 & 0.49 \\
Bra & - & 1.00 & 0.79 & 0.71 & - & 1.00 & 0.66 & 0.46 \\
Chi & - & - & 1.00 & 0.77 & - & - & 1.00 & 0.61 \\
Mex & - & - & - & - & 1.00 & - & - & - & 1.00 \\
\hline \multicolumn{9}{c}{} & \multicolumn{1}{c}{$1971-1987$} \\
\hline & Arg & Bra & Chi & Mex & Arg & Bra & Chi & Mex \\
Arg & 1.00 & 0.59 & 0.53 & 0.76 & 1.00 & 0.41 & 0.82 & 0.71 \\
Bra & - & 1.00 & 0.71 & 0.59 & - & 1.00 & 0.47 & 0.47 \\
Chi & - & - & 1.00 & 0.41 & - & - & 1.00 & 0.65 \\
Mex & - & - & - & 1.00 & - & - & - & 1.00 \\
\hline
\end{tabular}




\section{Figure 1: Common Factors}

Comparison of the first two common factors (F1, F2) extracted from series detrended with the Hodrick-Prescott (HP) or the Baxter-King (BK) filters.
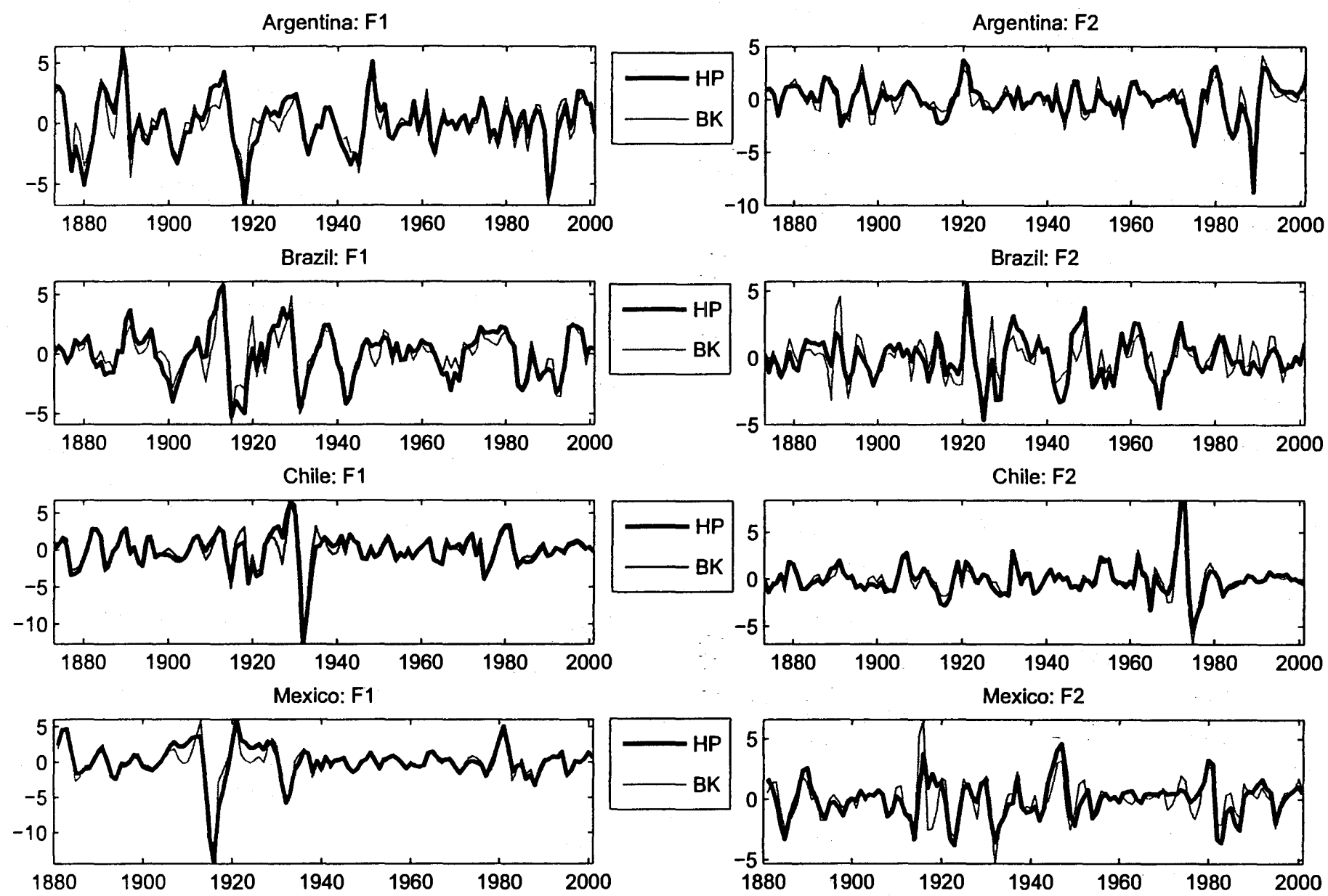
Figure 2: Actual and Backcasted Values of Cyclical Growth

Comparison between backcasted values, actuals, and other researchers' estimates of actual (Other) for Argentina, Brazil, Chile, and Mexico. All reg. denotes backcasted values that use all available regressors. The backcasting equation estimates the factors using either the Stock and Watson (2002) approach with $r$ static factors (SW(r)) or the Forni et al (2000) dynamic factor approach with $\mathrm{q}, \mathrm{r}$ dynamic and static factors, respectively (FHLR(q,r)). Each backcasting equation includes a constant term. The backcasting sample is 1870-1950 for all countries except Mexico (1878-1950).

Panel A: Argentina
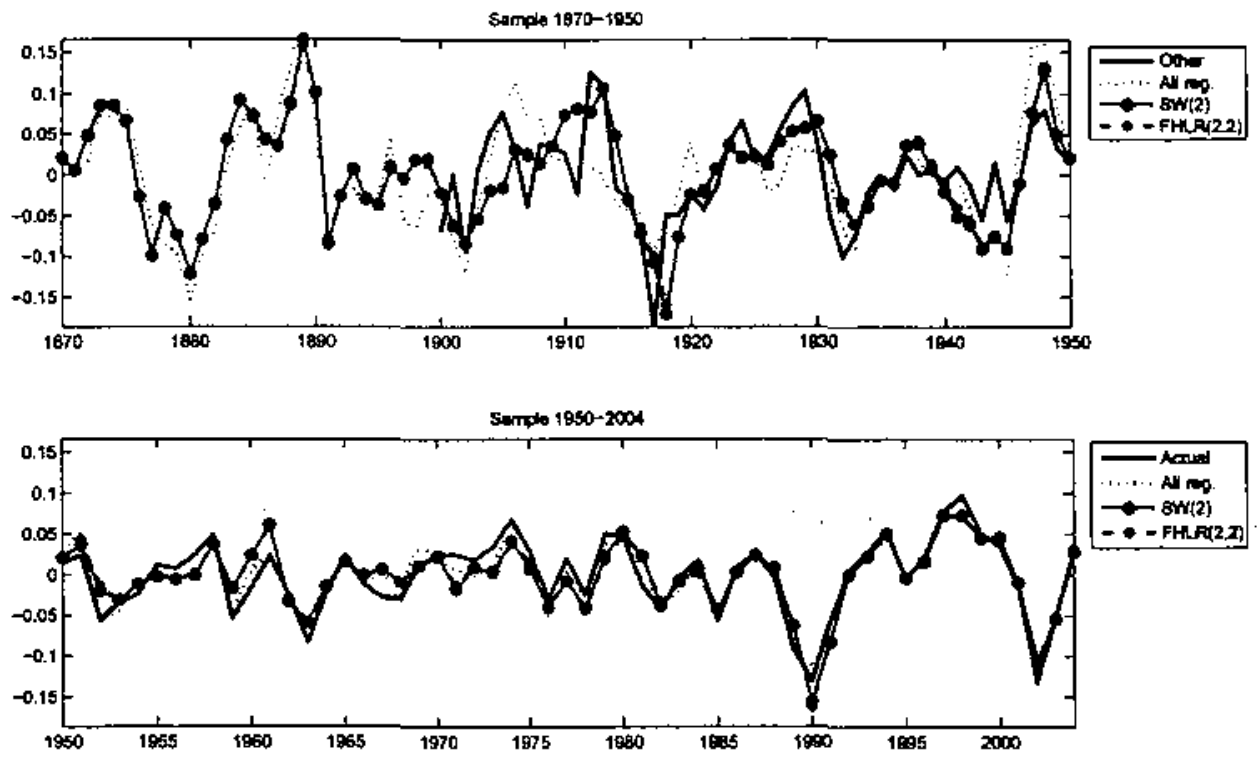

Panel B: Brazil
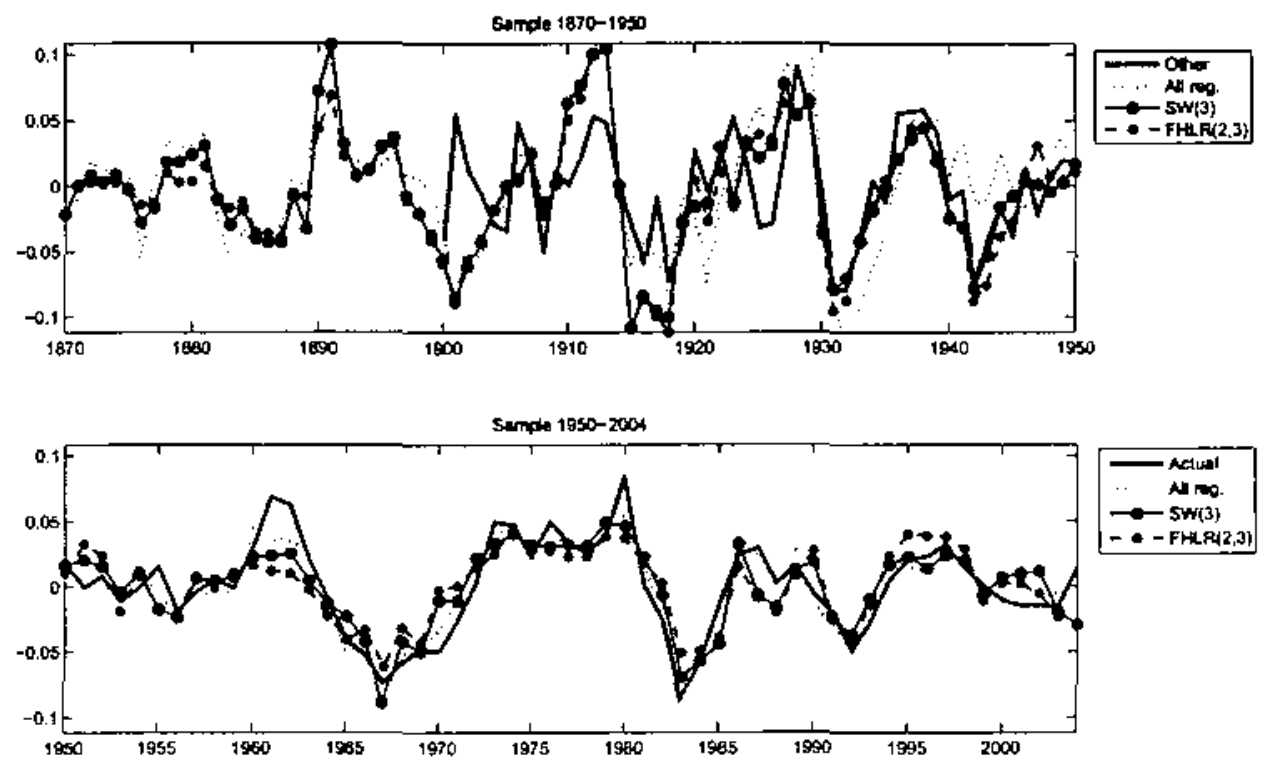
Panel C: Chile
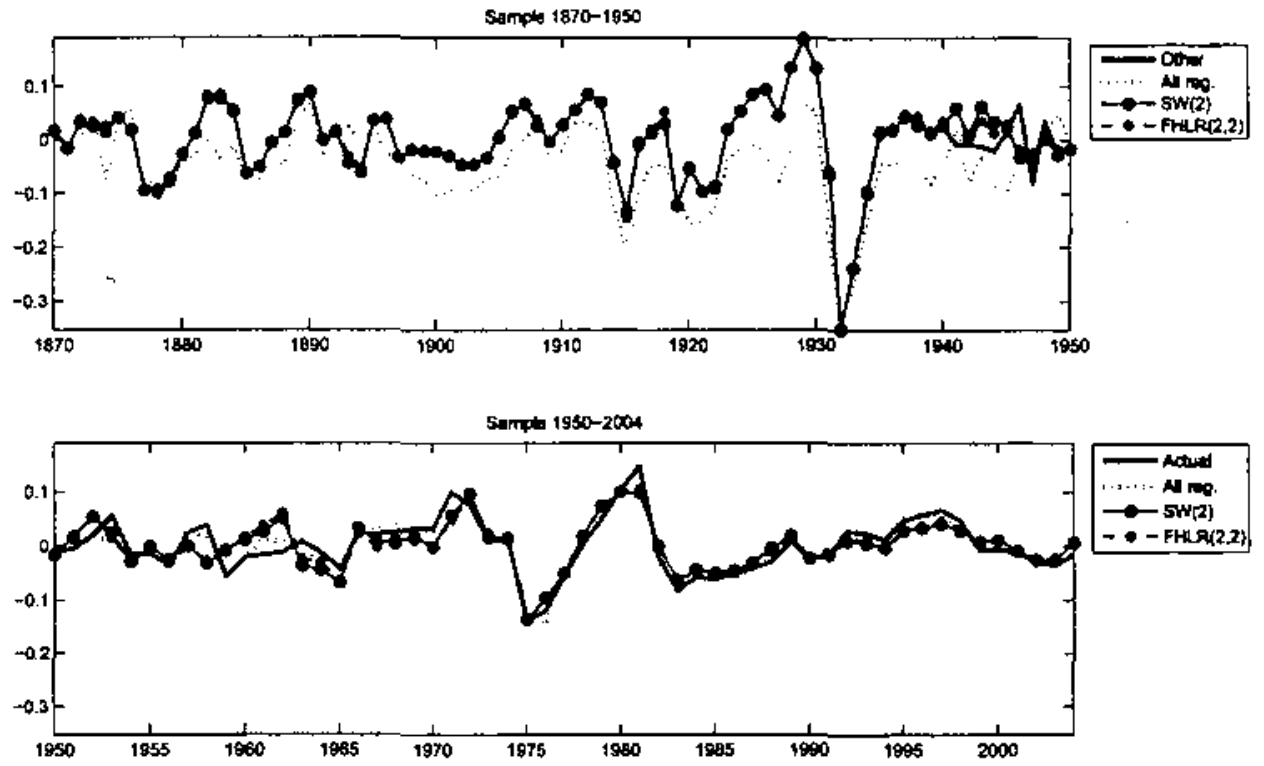

Panel D: Mexico
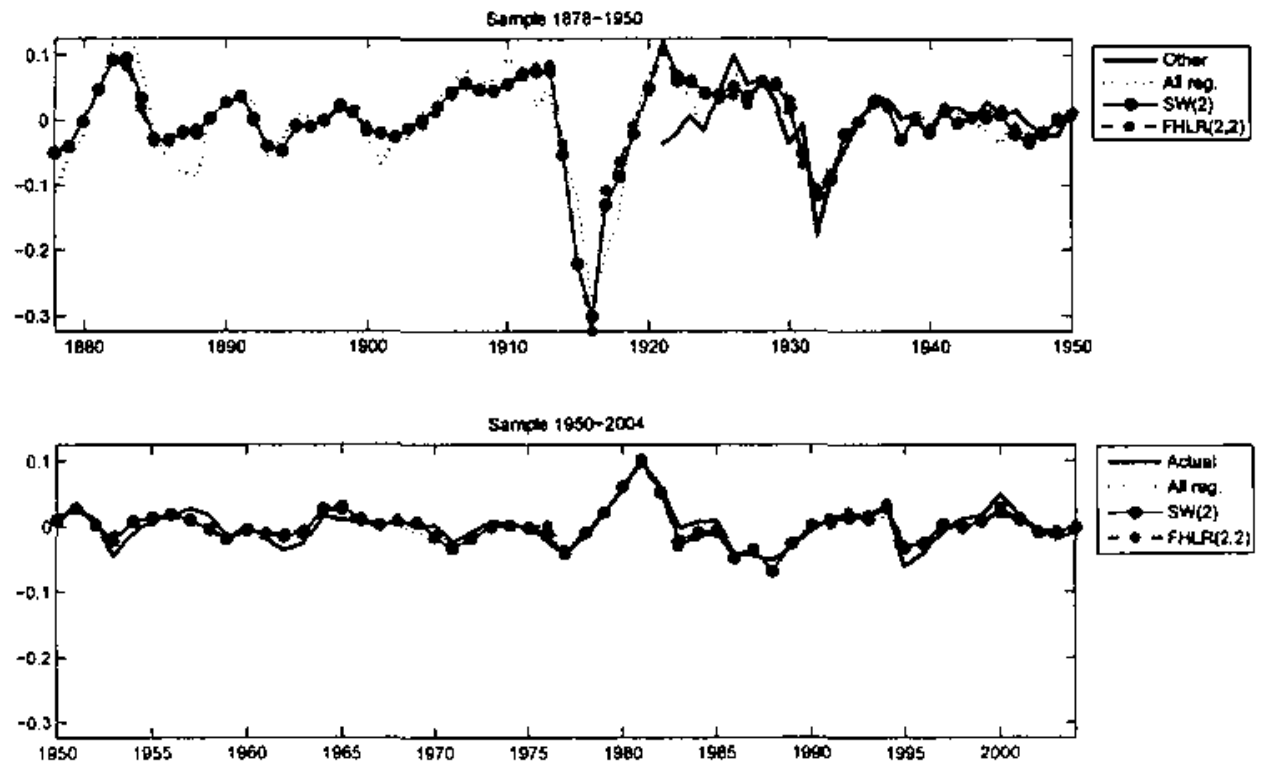
Figure 3: Robustness Check

Comparison of actual and backcasted values of business cycle. For each year the figures show the minimum and maximum backcasted value of cyclical output growth across models estimated using different numbers of factors and different data samples to estimate the backcasting equation or to extract common factors.
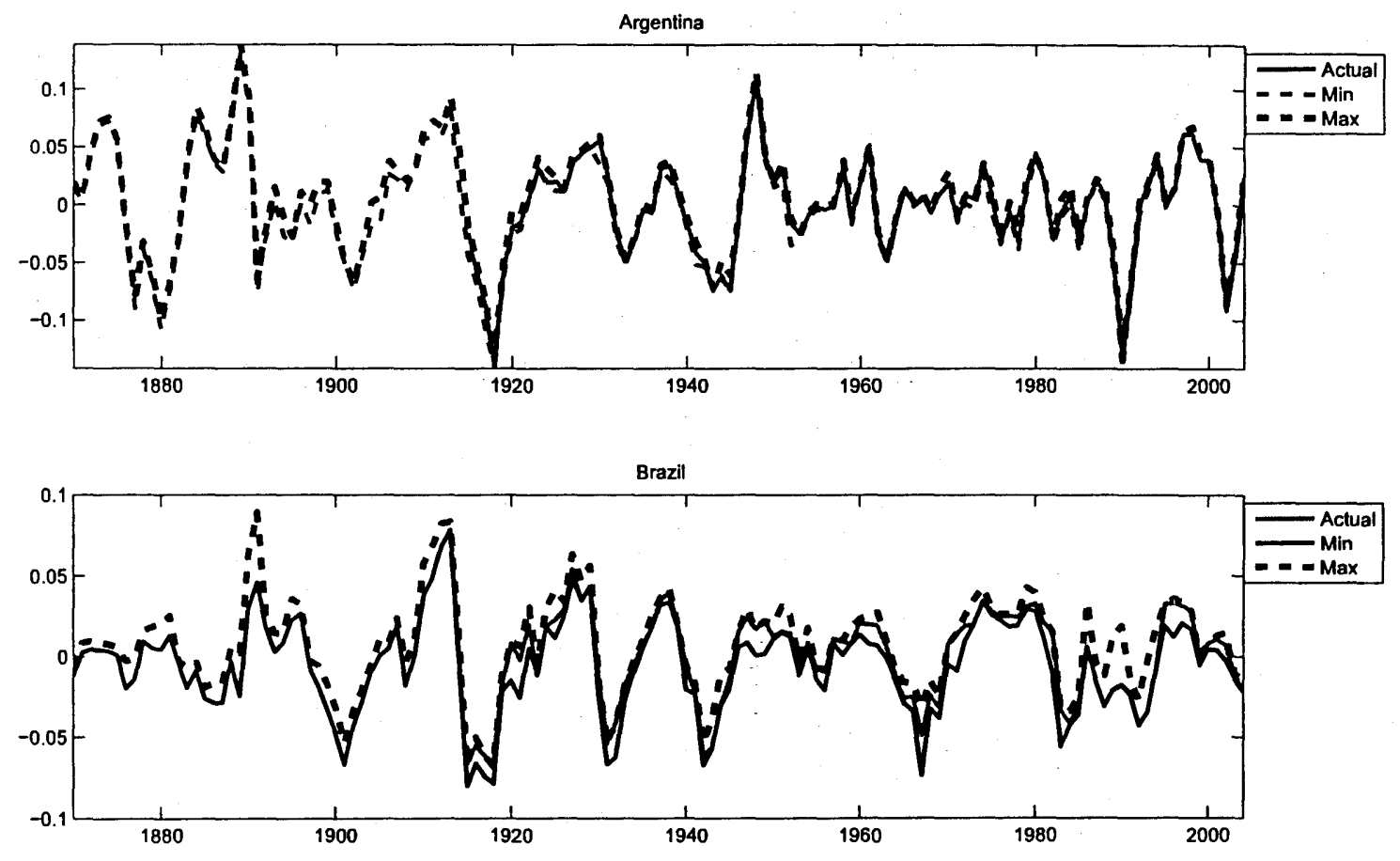

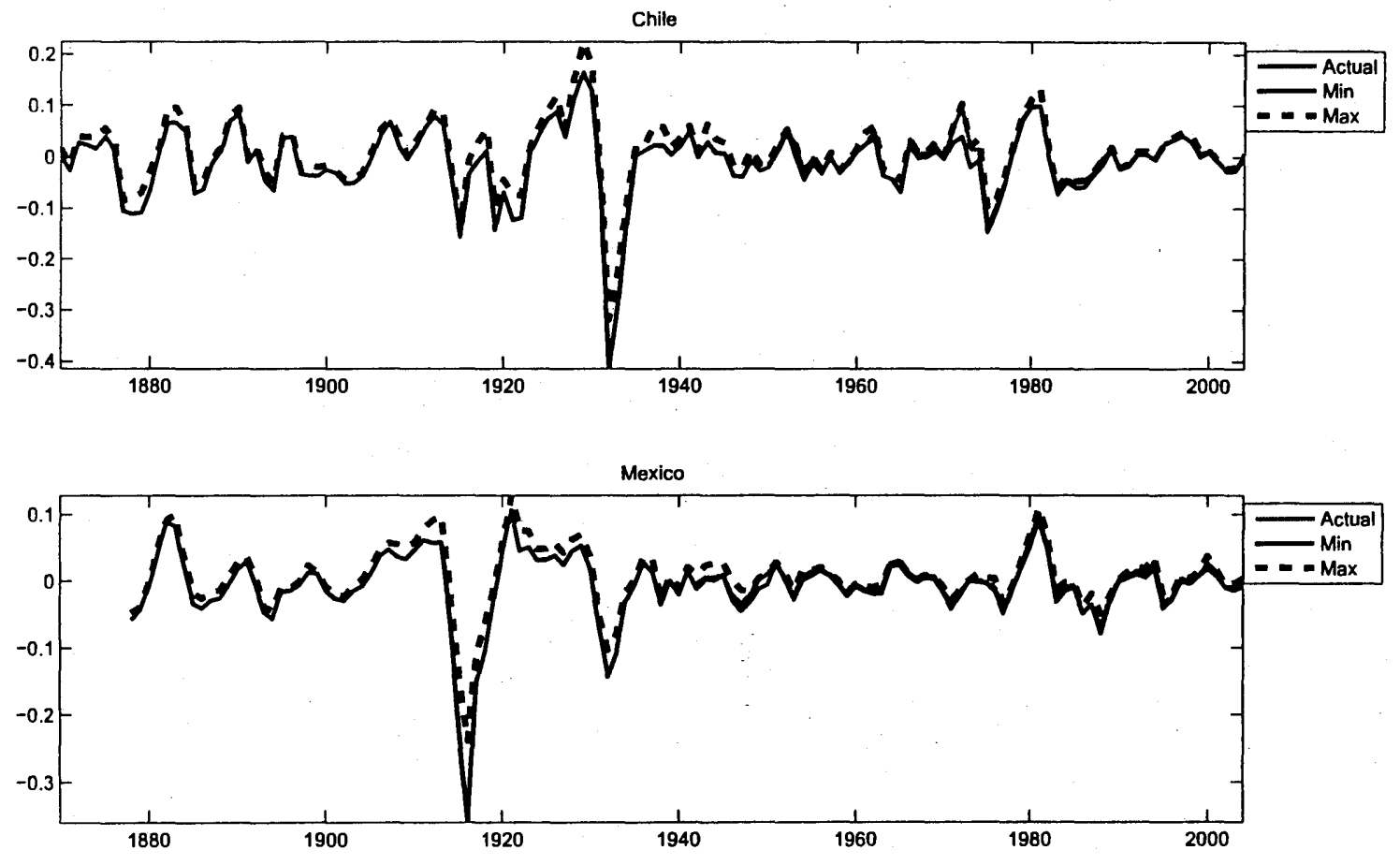


\section{Figure 4: Recursive Parameter Estimates}

Recursive estimates of the coefficients used to obtain business cycle estimates from the backcasting equation. The first sample is 1960-2004, the last sample is 1920-2004, except for Chile (1940-2004). $c$ is the intercept while bl,b2, and b3 are the slope coefficients for the first three common factors.
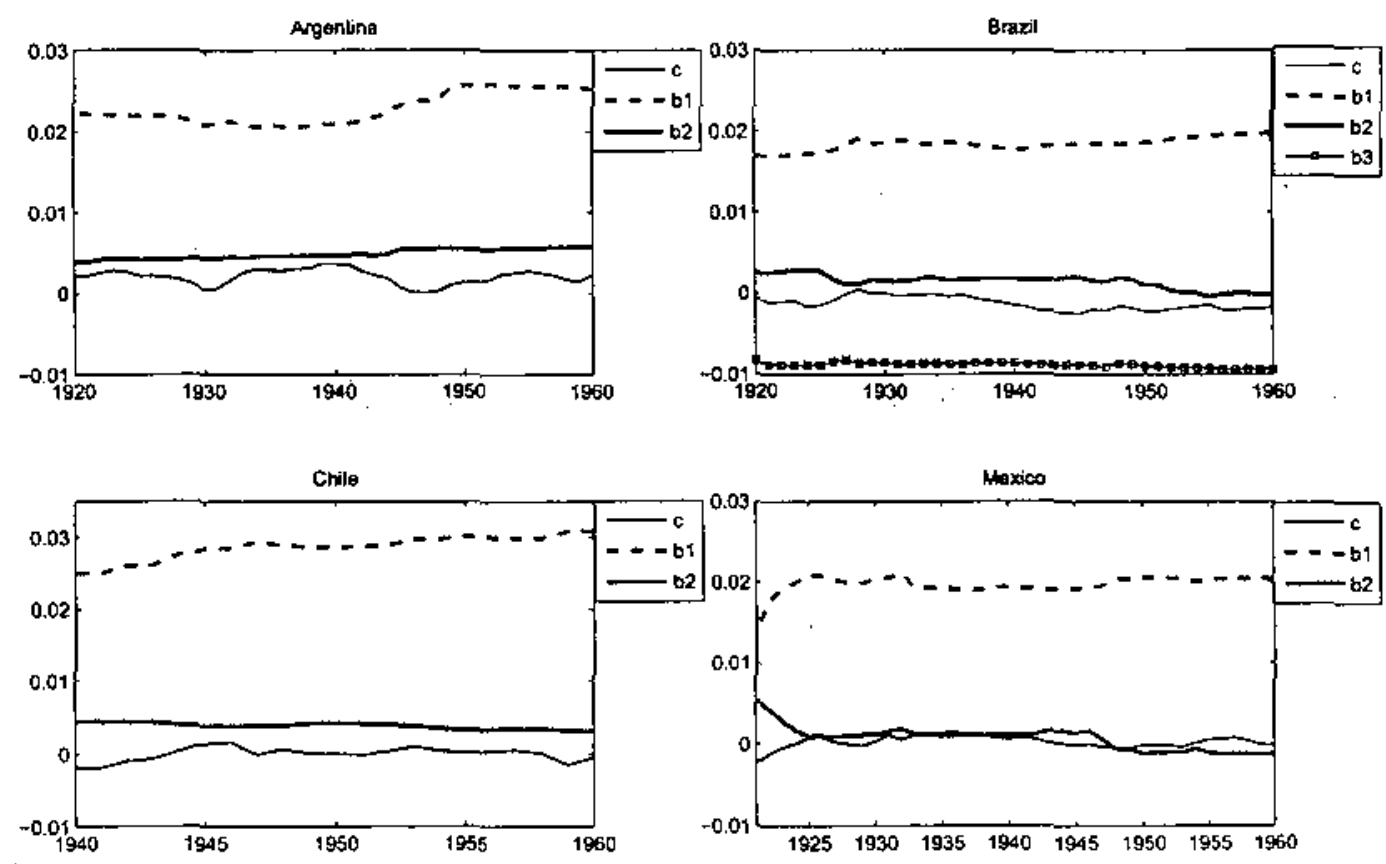

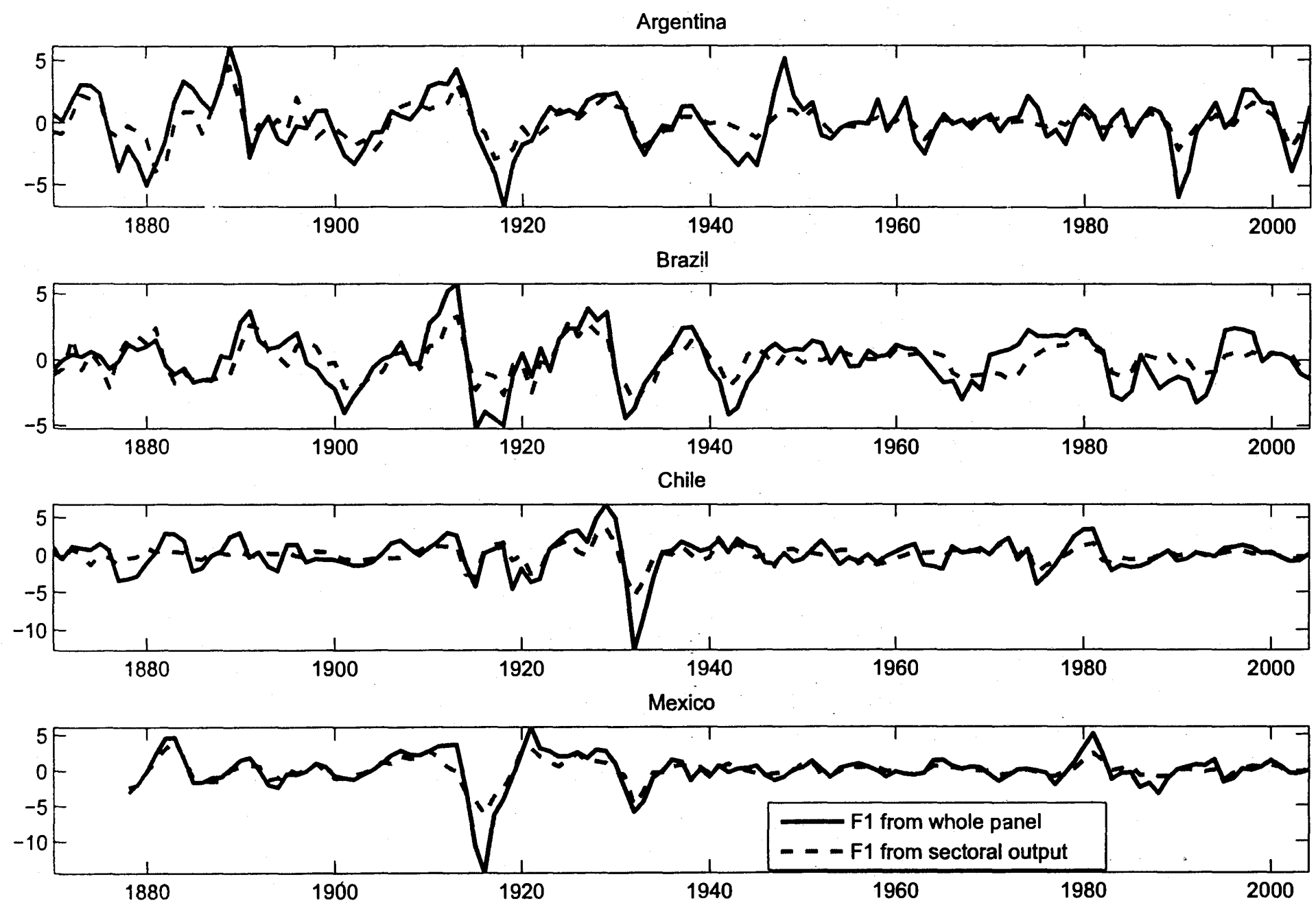
Figure 6: Actual and Backcasted Values of the US Business Cycle

Comparison of actual and backcasted values of business cycle for the US. Actual values are based on the Balke and Gordon series. All reg. denotes backcasted values that use all available regressors. The backcasting equatiou estimates the factors using either the Stock and Watson (2002) approach with r static factors (SW( $r$ )) or the Forni et al (2000) dynamic factor approach with $q, r$ dynamic and static factors, respectively (FHLR( $q, r)$ ). Each backcasting equation includes a constant term. The backcasting sample is 1870-1950.
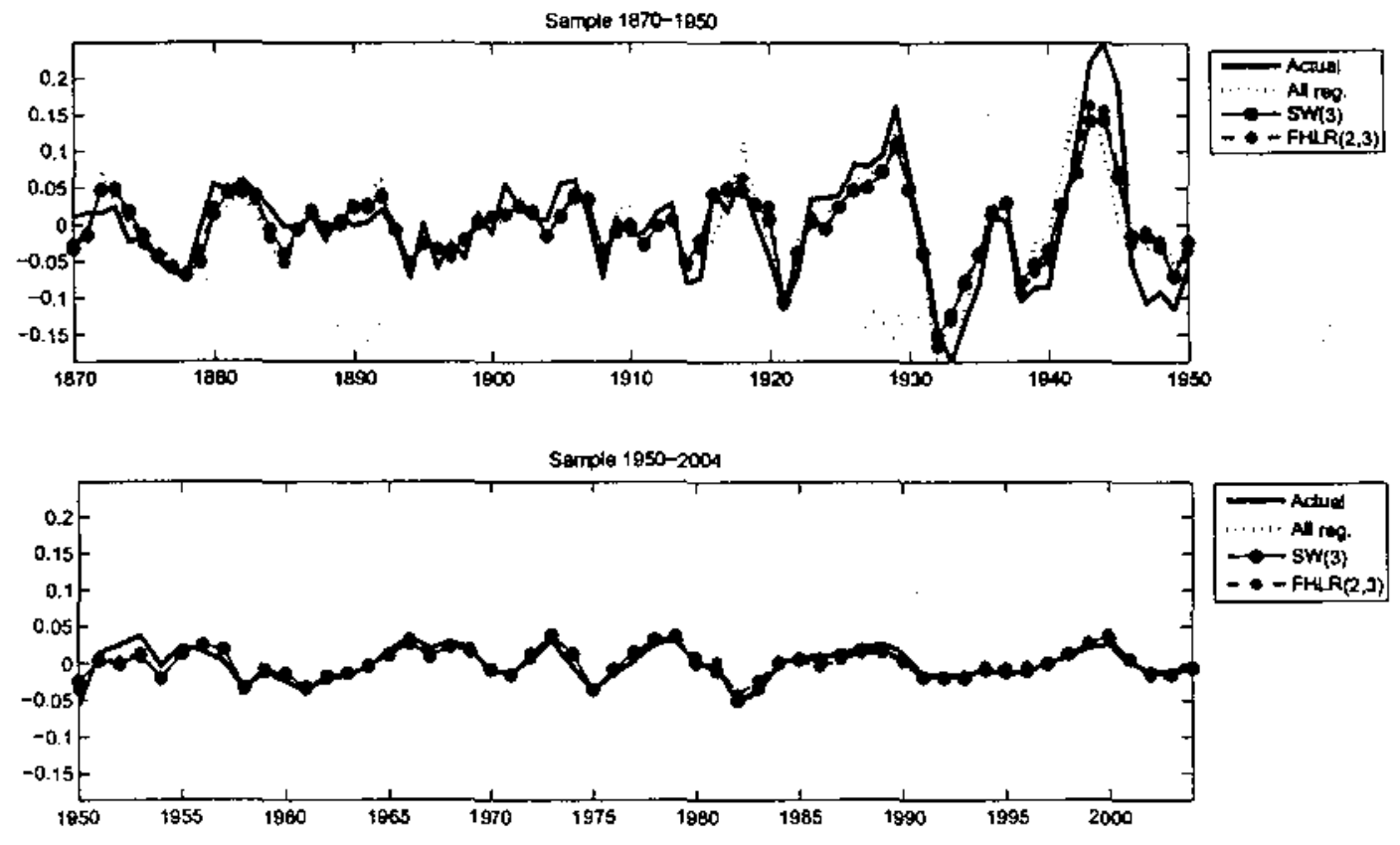


\section{Figure 7: Historical Charts}

Historical event charts. The panels report the backcasted business cycle for Argentina, Brazil, Chile and Mexico against world economic events (dark sharted area) and count ry-specific events (light shaded area).

Panel A: 1870-1949
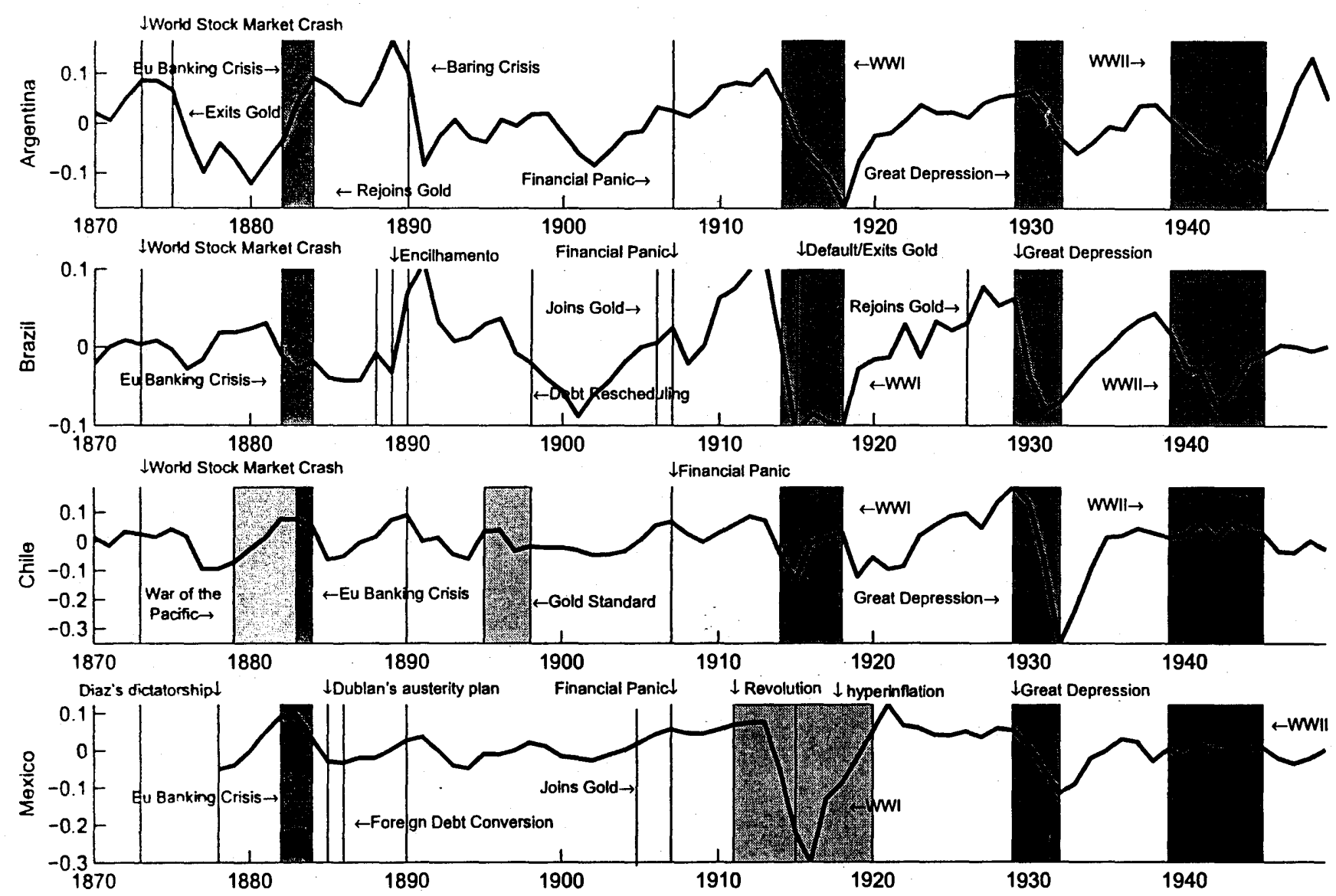
Panel B: 1950-2004

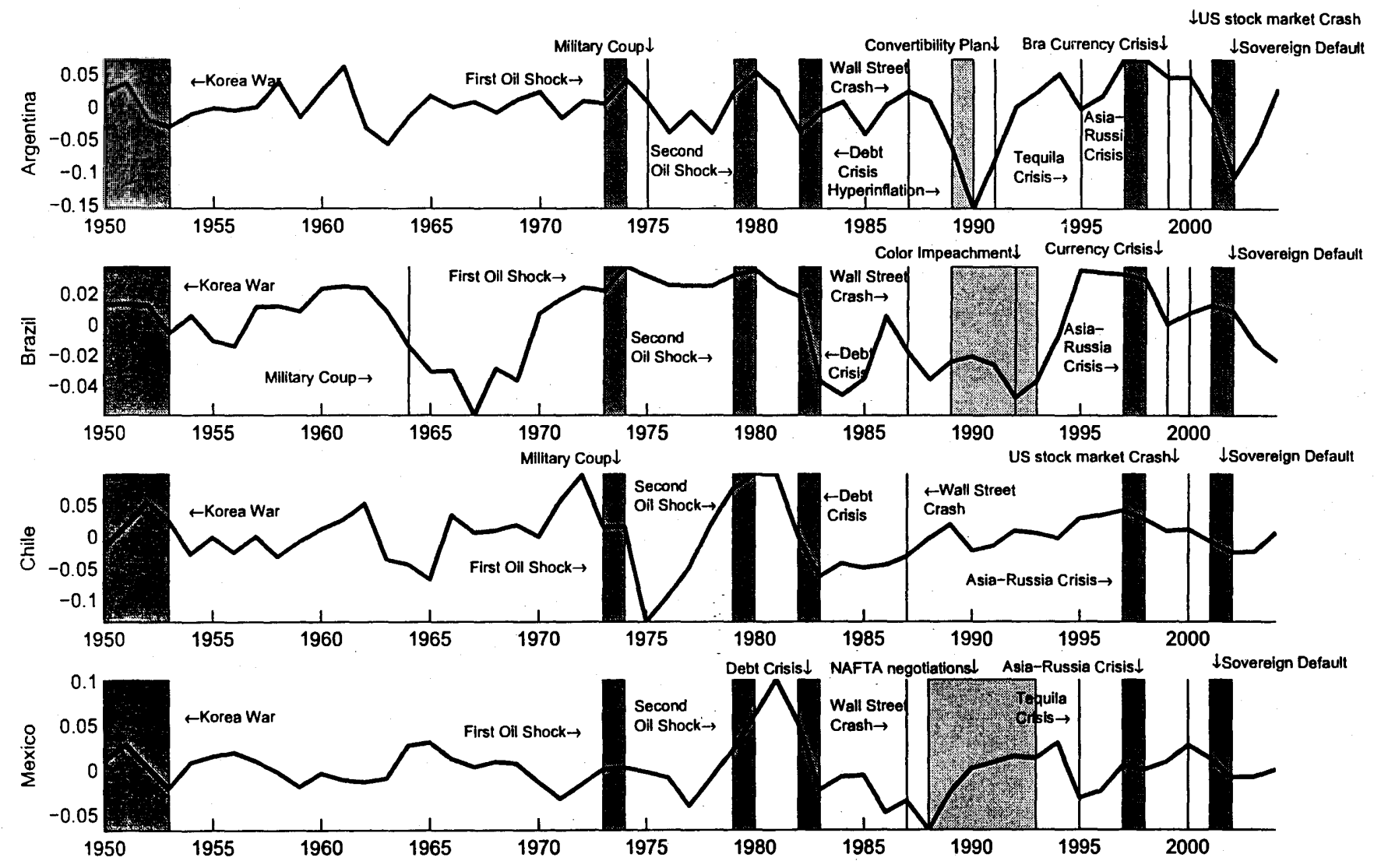




\section{Figure 8: Volatility}

The figure reports 10-Year rolling window estimates of standard deviations of the backcasted business cycle. The top panel reports estimates for Argentina, Brazil. Chile, and Mexico. The backcasted values are based on a model using two common static factors (three for Brazil). The bottom panel reports estimates for the LA-4 region.
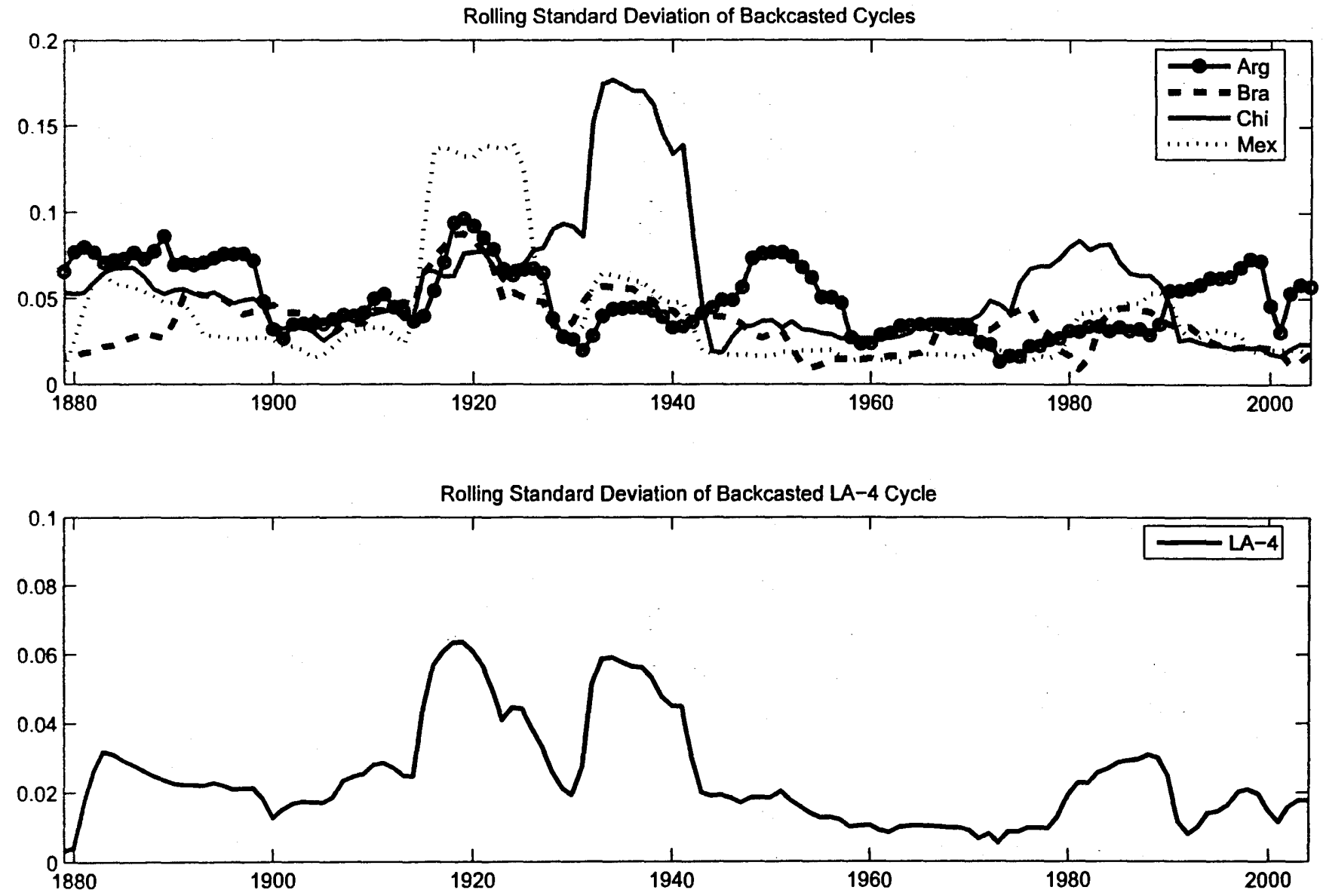


\section{Data Construction and Sources}

\section{Argentina}

\section{Agricultural Output}

1900-1960: Banco Central de Argentina (1976)

1961-2004: World Bank, World Development Database.

\section{Industrial Output}

1875-1960: della Paolera and Taylor (2003)

1961-2004: World Bank, World Development Database.

\section{Transport Output}

1870-1960: Geometric weighted average of passengers and tons of freight per kilometers times total railway road extension; then spliced in 1913 with the index provided in Carlos F. Diaz-Alejandro, 1970, Essays on the Economic History of the Argentine Republic. Yale.

\section{Cement Consumption}

1870-1913: Total cement imports in tons from the United Kingdom and the United States, which together accounted for no less than between 60 to 70 percent of Argentina's total cement imports. The sources are the United Kingdom, Board of Trade, Annual Statements of the Trade of the United Kingdom with Foreign Countries and British Possessions. London: HMSO. Commerce and Navigation, several issues; and the United States, Foreign Commerce, Navigation and Tonnage of the United States, Washington, DC: Department of Labor, several issues. Because a local cement industry was non-existing before World War I, all domestic consumption of cement was then met by imports. So this newly constructed series for the period should be expected to a good proxy for domestic construction activity.

1913-2000: Oxford Latin American Economic History database, available at http://oxlad.qeh.ox.ac.uk/.

2001-2004: Instituto Nacional de Estadisticas y Census de la Republica Argentina, available at: www.indec.mecon.ar/.

\section{Fixed Investment}

1870-1884: Capital goods imports from the United Kingdom and the United States (converted into equivalent pounds sterling) and deflated by the UK capital good deflator taken from Charles H. Feinstein, 1972, Statistical Tables of National Income, Expenditure and Output of the United Kingdom, 1855-1965, Cambridge. Since the 
domestic capital goods industry was virtually non-existent in Argentina before World War I (being in fact relatively negligible before WWII-see Diaz-Alejandro, 1970), and because the United Kingdom and the United States were the two most important suppliers of capital goods to Argentina, such imported capital goods series should be expected proxy very well aggregate fixed capital formation in the country in those early decades.

1885-1960: della Paolera and Taylor (2003).

1961-2004: International Financial Statistics (IFS), International Monetary Fund.

\section{Central Government Expenditures and Revenues}

1870-1960: Brian M. Mitchell, 1998, International Historical Statistics: The Americas, London.

1961-2004: Luis A.V. Catão and Marco E. Terrones, 2005, "Fiscal Deficits and Inflation," Journal of Monetary Economics, 52, pp. 529-554. Both series are expressed in real terms by deflating them by the consumer price index (CPI).

\section{Narrow (M0) and Broad Money (M2)}

1870-1960: Mitchell, op cit.

1961-2004: IFS. Both series expressed in real terms by deflating them by the CPI.

\section{Consumer Price Index (CPI)}

1870-1913: Catão and Solomou (2005).

1914-1960: della Paolera and Taylor (2003)

1961-2004: IFS.

\section{Average Interest Rate on Domestic Public Bonds}

1870-1913: `Monetary and Banking Experiments in Argentina: 1861-1930’, Paper presented at the conference, 'Economic Growth in the Long Run: Argentina, Brazil and Mexico, 1870-1950' at the Institute of Latin American Studies, University of London, March, 1992.

1914-1993: della Paolera and Javier Ortiz, 1995, Dinero, Intermediacion Financiera y nivels de actividad en 110 anos de historia economica Argentina. Documentos de Trabajo 36 (December), Universida Torcuato di Tella.

1993-2004: IFS (line 60p). Real interest rate series obtained by deflating annual nominal yields by current period CPI inflation. 


\section{Export and Import volumes and Net Barter Terms of Trade}

1870-1913: Catão and Solomou (2005).

1914-1960: Oxford Latin American Economic History database, available at http://oxlad.qeh.ox.ac.uk/.

1961-2004: IFS.

\section{Real Effective Exchange Rate}

1870-1913: Catão and Solomou (2005).

1914-2004: CPI-based geometric weighted averages of Argentina's real bilateral exchange rates with its eight largest trading partners (covering between 67 and 80 percent of visible trade). ${ }^{20}$ Fisher ideal indices were derived for the sub-periods 1914-1946 and 1946-2004 (based on 1913 and 1938, and 1960 and 2000 weights respectively), and then spliced at 1946. Nominal exchange rates for the entire postwar period are market rates underlying Carmen M. and Kenneth S. Rogoff, 2004, "The Modern History of Exchange Rate Arrangements: A Reinterpretation," Quarterly Journal of Economics, CXIX, No.1, pp.1-48.

\section{Net Foreign Capital Inflows}

1870-1960: Obtained by splicing the series on UK capital flows to Argentina provided in Stone, Irving, 1999, The Global Export of Capital from Great Britain, 1865-1914: A Statistical Survey, New York, with a post-1884 series on net capital inflows constructed as changes in end-year net international reserves expressed in US\$ million (obtained from Gerardo della Paolera, 1988, "How the Argentine Economy Performed During the International Gold Standard: A Re-examination", PhD thesis, University of Chicago for 1870-1913 then with the Cavallo-Mundlak series, as kindly supplied by Alan Taylor) minus the current account balance (also expressed in US\$ millions) provided in della Paolera and Taylor (2003). The splicing of the two series is warranted by the fact that the UK was by far the most important source of foreign capital flows to Argentina before World War I (and particularly prior to 1890), and evidence that the two series co-move tightly together in the 18841913 period, with a correlation coefficient of 0.81 .

\footnotetext{
${ }^{20}$ The choice of GDP deflator rather than a CPI-based index was determined by the deficiencies of the existing CPI series during the period 1870-1913, compared to an existing series based on production weights (therefore mimicking a GDP deflator) which covers a much extensive range of products and constructed based on weights from national production censuses.
} 
1961-2004: Also obtained as the difference between changes in international reserves and the current account balance, both as reported by the IFS. The resulting nominal series in U.S. dollars was then deflated by the U.S. wholesale price index (WPI) obtained from Global Financial Database for the period 1870-1947 and the IFS for 1948-2004.

\section{Wages}

1870-1913: Jeffrey G. Williamson, "The Evolution of Global Labor Markets Since 1830", Explorations in Economic History, 32 (2), 1995, pp. 141-96.

1914-1980: della Paolera and Taylor (2003).

1981-2004: IMF's WEO database. This series was then deflated by CPI to obtain the real wage index.

\section{Foreign 3-month bill rate}

1870-1920: Annual average yields of 3-month bills on the London market provided in Sidney Holmer and Richard Sillas, 1996, A History of Interest Rates, Rutgers.

1921-2004: Annual average yields of the US 3-month Treasury Bill provided in the same source. The choice of 1920 as the splicing point was due to the unavailability of the US instrument prior to 1920. Both series were deflated by the respective countries' CPI inflation, obtained from Catao and Solomou (2005) for 1870-1913, Mitchell, op cit (1914-1960) and the IFS (1961-2004).

\section{Foreign Output}

Sum of French, German, U.K., and U.S. GDPs, all expressed in 1990 PPP constant dollars from Maddison (2003).

\section{Population at mid-year}

1870-1960: Maddison (2003).

1961-2004: IFS (2003).

\section{Brazil}

\section{Agricultural and Manufacturing Output}

1900-1946: Haddad (1978).

1947-2004: Instituto Brasileiro de Geografia e Estatistica, available at http://www.IBGE.gov.br 


\section{Transport Output}

1870-1907: Average of freight and passenger transported in railways, using 1908 weights provided in Haddad (1978).

1908-1946: Haddad (1978).

1947-2004: Instituto Brasileiro de Geografia e Estatistica, available at http://www.IBGE.gov.br.

\section{Communications Output}

1870-1907: Average of mail and telegraph traffic in the national postal system, weighted according to current 1889 values provided in Instituto Brasileiro de Geografia e Estatistica, 1987. Estatisticas Históricas do Brasil, Rio de Janeiro, IBGE.

1908-1946: Haddad (1978).

1947-2004: Instituto Brasileiro de Geografia e Estatistica, available at http://www.IBGE.gov.br

\section{Cement Consumption}

1870-1901: Cement imports from France, Germany, the United Kingdom, and the United States, obtained from these countries' own trade statement data (see above). Since these four countries accounted for between 75 and 85 percent of total Brazilian imports (see IBGE, op.cit., pp. 545-49) and all cement consumed in Brazil at the time was imported, this newly constructed series is very representative of aggregate cement consumption and hence a good proxy for domestic construction activity.

1902-1945: Anibal V. Villela and Wilson Suzigan, 1975, Politica do Governo e Crescimento da Economia Brasileira 1889-1945, pp. 423.

1945-2004: Instituto Brasileiro de Geografia e Estatistica, available at http://www.IBGE.gov.br; and IPEA database.

\section{Machinery Investment}

1870-1913: Wilson Suzigan, Industria Brasileira. Origens e Desenvolvimento, São Paulo, 1986.

1913-2004: Instituto Brasileiro de Geografia e Estatistica, available at http://www.IBGE.gov.br 


\section{Central Government Expenditures and Revenues}

1870-1960: IBGE, op. cit.

1961-2004: Luis A.V. Catão and Marco E. Terrones, 2005, "Fiscal Deficits and Inflation," Journal of Monetary Economics, Vol. 52, pp. 529-554. Both series are expressed in real terms by deflating them by the GDP deflator.

Narrow (M1) and Broad Money (M2)

1870-1960: IBGE, op. cit.

1961-2004: IFS. Both series expressed in real terms by deflating them by the GDP deflator.

\section{GDP deflator}

1870-1913: Catão and Solomou (2005).

1914-1960: IBGE, op cit.

1961-2004: IFS.

\section{Domestic Interest Rate}

1870-1961: yields on government perpetuities (“apolices”). Pre-1930 data kindly provided by Bill Summerhill and Gail Trinner based on their research with Brazilian historical archieves. Post-1930 data from Claudio Contador, 1975, O Mercado de Ativos Financeiros no Brasil. Perspectiva historica e comportamento recente. Rio de Janeiro.

1965-1980: Equivalent nominal yield on inflation indexed public bonds (ORTNs), from Goldsmith, op. cit. The gap between the apolice series and the ORTN series was bridged by linear interpolation.

1981-2004: Money market interest rate from IFS. Real interest rate series obtained by deflating annual nominal yields by current annual percentage changes in the GDP deflator.

\section{External Interest Rate Spread}

1870-1913: Mauro, Paolo, N. Sussman and Y. Yafeh, 2002, "Emerging Market Spreads: Then versus Now," Quarterly Journal of Economics, CXVII.

1914-1956: Global Financial Data.

1968-1986: Eliana Cardoso and Albert Fishlow, "The Macroeconomics of Brazilian External Debt," in J. Sachs (ed.), Developing Country Debt and Economic Performance. Chicago, pp. 269-391 
1987-1993: Estimated as the one-year libor interest rate plus a 400 basis points spread minus the US 10-year bond interest rate.

1993-2004: IMF's global data source database. Real interest rate series obtained by deflating annual nominal yields by current period CPI inflation.

\section{Export and Import volumes and Net Barter Terms of Trade}

1870-1913: Catão and Solomou (2005).

1914-1960: Instituto Brasileiro de Geografia e Estatistica, available

at http://www.IBGE.gov.br

1961-2004: IFS.

\section{Real Effective Exchange Rate}

1870-1913: Catão and Solomou (2005).

1914-2004: GDP deflator-based geometric weighted averages of Brazil's real bilateral exchange rates with its eight largest trading partners (covering between 64 and 75 percent of visible trade). Fisher ideal indices were derived for the sub-periods 1914-1946 and 1946-2004 (based on 1913 and 1938, and 1960 and 2000 weights respectively), and then spliced at 1946. Nominal exchange rates for the whole postWWII period are market rates underlying Carmen M. and Kenneth S. Rogoff, 2004, "The Modern History of Exchange Rate Arrangements: A Reinterpretation," Quarterly Journal of Economics, CXIX, No.1, pp.1-48.

\section{Wages}

1870-1940: Jeffrey G. Williamson, “The Evolution of Global Labor Markets Since 1830," Explorations in Economic History, 32 (2), 1995, pp. 141-96.

1940-1955: IBGE, op cit..

1955-1976: Raymond Goldsmith, 1986, O Desenvolvimento Financeiro do Brasil, São Paulo.

1977-2004: IBGE, op cit..

\section{Foreign 3-month bill rate and Foreign Output}

The same as for Argentina.

\section{Population at mid-year}

1870-1960: Maddison (2003). 
1961-2004: IFS (2003).

\section{Chile}

\section{Agriculture, Manufacturing and Mining Output}

1870-1960: Juan Braun, Matías Braun, Ignacio Briones, José Diaz, Rolf Luders and Gert Wagner, 2000, "Economía Chilena 1810-1995: Estadísticas Históricas,"

Documento de Trabajo No. 187, Catholic University of Chile, Instituto de Economía.

1961-2004: World Development database, World Bank, and Central Bank of Chile.

\section{Machinery Investment}

1870-1900: Capital goods imports from the United Kingdom and the United States (converted into equivalent pounds sterling) and deflated by the UK capital good deflator taken from Charles H. Feinstein, 1972, Statistical Tables of National Income, Expenditure and Output of the United Kingdom, 1855-1965, Cambridge.

1901-1990: Andre Hoffman, 2000, The Economic Development of Latin America in the Twentieth Century, Cheltenham (pp. 190-91, Table D2).

1991-2004: Central Bank of Chile, ibid.

\section{Central Government Expenditures and Revenues}

1870-1960: Brian M. Mitchell, 1998, International Historical Statistics: The Americas, London.

1961-2004: Luis A.V. Catão and Marco E. Terrones, 2005, "Fiscal Deficits and Inflation," Journal of Monetary Economics, Vol. 52, pp. 529-554. Both series are expressed in real terms by deflating them by the consumer price index (CPI).

\section{Narrow Money (M0) and Broad Money (M2)}

1870-1878: M0 calculated as paper money issued minus banks' cash-in-vault, both taken from Llona Rodriguez, Agustin, Chilean Monetary Policy 1870-1925, PhD thesis, Boston University; M2 from Braun et al, op.cit.

1879-1960: M0 from Mitchell, op cit.; M2 from Braun et al. op.cit.

1961-2004: IFS. Both series expressed in real terms by deflating them by the CPI.

\section{Mortgage Credit}

1870-1995: Braun et al. (1995).

1995-2004: Central Bank of Chile. 


\section{Consumer Price Index (CPI)}

1870-1913: Catão and Solomou (2005).

1914-1960: Mitchell, op cit.

1961-2004: IFS.

\section{Domestic Interest Rate}

1870-1993: Bank lending rate from Braun et al, op cit.

1993-2004: IFS (line 60p). Real interest rate series obtained by deflating annual nominal yields by current period CPI inflation.

\section{Export and Import volumes and Net Barter Terms of Trade}

1870-1913: Catão and Solomou (2005).

1914-1960: Braun et al, op.cit.

1961-2004: IFS.

\section{Real Effective Exchange Rate}

1870-1913: Catão and Solomou (2005).

1914-2004: CPI-based geometric weighted averages of real bilateral exchange rates with up to Chile's twenty largest trading partners (covering between 79 and 93 percent of visible trade). Fisher ideal indices were derived for the sub-periods 1914-1946 and 1946-2004 (based on 1913 and 1938, and 1960 and 2000 weights respectively), and then spliced at 1946. Nominal exchange rates for the whole postWWII period are market rates underlying Carmen M. and Kenneth S. Rogoff, 2004, "The Modern History of Exchange Rate Arrangements: A Reinterpretation," Quarterly Journal of Economics, CXIX, No.1, pp.1-48.

\section{Wages}

1870-1995: Real wage index from Braun et al, op.cit.

1995-2004: Average nominal wage index from IMF's WEO database, deflated by CPI.

\section{Population at mid-year}

1870-1960: Maddison (2003).

1961-2004: IFS (2003). 


\section{Mexico}

\section{Agricultural Output}

1878-1910: Colegio de México, 1960, Estadísticas Economicas del Porfiriato, p.61. Refers to export crop sub-index. Converted from a fiscal to calendar year basis by the averaging of two successive years.

1911-1921: Index constructed as a weighted average of the output of ten main crops (beans, corn (maiz), cotton, coffee, garbanzo, rice, sisal, sugar, and tomatoes) weighted by their 1900 (normalized) share in total value of agricultural production. The information on individual crop output was taken from INEGI, 1992, Estadísticas Historicas de Mexico, Mexico.

1921-1960: Leopoldo Solis, 1975, La Realidade Económica Mexicana. Retrovision y Perspectivas. Mexico.

1961-2004: World Development database, World Bank, and INEGI, available at http://www.inegi.gob.mx/est/default.asp?c=1601.

\section{Manufacturing Output}

1878-1910: Colégio de México, op. cit, p.105. Prior to 1892, the series reflects solely changes in the index of domestic textile production taken from Haber, Stephen, Armando Razo and Noel Maurer, 2003, The politics of property rights: Political instability, credible commitments, and economic growth in Mexico, 1876-1929. Cambridge. Figures for 1879-1882, 1884-87, and 1890 derived by linear interpolation due to the gaps in the original source.

1910-1921: INDEC, op.cit.

1921-1960: Solis, 1975, op.cit.

1961-2004: World Development database, World Bank, and INEGI, available at http://www.inegi.gob.mx/est/default.asp?c=1601.

\section{Mining Ouput}

1878-1910: Colégio de México, op. cit, p.135.

1911-1921: Weighted average of the output of ten main domestically produced metals (silver, gold, iron, graffite, lead, mercury, copper, zinc, antimonio, and lead) as well as oil, weighted according their 1900 value share in total mining output provided in the same source (pp.136-43).

1921-1960: Solis, 1975, op.cit. 
1961-2004: World Development database, World Bank, and INEGI, available at http://www.inegi.gob.mx/est/default.asp?c=1601.

\section{Transportation and Communications Output}

1870-1921: Weighted average of railway freight and passenger traffic (taken from John Coatsworth, Growth Against Development-The Economic Impact of Railways in Porfirian Mexico, Illinois) and postal service traffic, taken from Mitchell, op.cit.

1921-1960: Solis, 1975, op.cit.

1961-2004: World Development database, World Bank, and INEGI, available at http://www.inegi.gob.mx/est/default.asp?c=1601

\section{Cement Consumption}

1870-1931: Cement imports from the United Kingdom and the United States (by far the two main foreign suppliers), obtained from these countries' own trade statement data (see above). From 1906 onwards, when the first plants of domestic cement production began operations, we add their output (taken from the Oxford Latin American Economic History database, see above) to imports.

1932-2000: Oxford Latin American Economic History database, available at http://oxlad.qeh.ox.ac.uk

2001-2004: INEGI, op.cit.

\section{Machinery Investment}

1870-1925: Luis Catão, 2005, "Exchange Rate and Machinery Investment in Early Development: The Cases of Brazil and Mexico," International Monetary Fund. Unpublished.

1925-1940: Enrique Cardenas, 1987, Mexico's Industrialization during the Great Depression: Public Policy and Private Response, PhD thesis, Yale University. The index is based on the volume of imported capital goods.

1941-1993: Hoffman, op.cit.

1994-2004: INEGI, op.cit.

\section{Central Government Expenditures and Revenues}

1870-1960: IBGE, op. cit. 
1961-2004: Luis A.V. Catão and Marco E. Terrones, 2005, "Fiscal Deficits and Inflation," Journal of Monetary Economics, Vol. 52, pp. 529-554. Both series are expressed in real terms by deflating them by the CPI deflator.

\section{Narrow (M0) and Broad Money (M2)}

1870-1925: Catão, op. cit.

1926-1960: INEGI, op.cit.

1961-2004: IFS. Resulting real series was obtained by CPI deflation.

CPI

1870-1913: Catão and Solomou (2005).

1914-1917: Interpolated assuming relative PPP, given that no domestic data seem available for the hyperinflation period. Assuming PPP is probably not very inaccurate since those years were characterizing by soaring inflation and a hyperinflation (see main text) which typically tends to align domestic price movements with the exchange rate.

1918-1940: Williamson, op.cit.

1941-1960: Mitchell, op.cit.

1961-2004: IFS.

\section{Export and Import volumes and Net Barter Terms of Trade:}

1870-1925: Catão (2005), op.cit.

1926-1940: Cardenas, op.cit.

1941-1960: INEGI, op.cit.

1961-2004: IFS.

\section{Real Effective Exchange Rate}

1870-1913: Catão and Solomou (2005).

1914-2004: CPI-based geometric weighted averages of Mexico's real bilateral exchange rates with its six largest trading partners (covering over 90 percent of visible trade). Fisher ideal indices were derived for the sub-periods 1914-1946 and 1946-2004 (based on 1913 and 1938, and 1960 and 2000 weights respectively), and then spliced at 1946. Nominal exchange rates for the whole post-WWII period are market rates underlying Carmen M. and Kenneth S. Rogoff, 2004, “The Modern 
History of Exchange Rate Arrangements: A Reinterpretation," Quarterly Journal of Economics, CXIX, No.1, pp.1-48.

\section{Wages}

1870-1940: Jeffrey G. Williamson, "The Evolution of Global Labor Markets Since 1830," Explorations in Economic History, 32 (2), 1995, pp. 141-96.

1940-1974: Mitchell, op cit..

1974-2004: WEO and IFS databases.

\section{Foreign 3-month bill rate}

1870-1920: Annual average yields of 3-month bills on the London market provided in Sidney Holmer and Richard Sillas, 1996, A History of Interest Rates, Rutgers.

1921-2004: Annual average yields of the US 3-month Treasury Bill provided in the same source. The choice of 1920 as the splicing point was due to the unavailability of the US instrument prior to 1920 . Both series were deflated by the respective countries' CPI inflation, obtained from Catao and Solomou (2005) for 1870-1913, Mitchell, op cit (1914-1960) and the IFS (1961-2004).

\section{Foreign Output}

US real GDP in 1990 PPP constant dollars from Maddison (2003).

\section{Population at mid-year}

1870-1960: Maddison (2003).

1961-2004: IFS (2003).

\section{United States}

\section{Agricultural Output}

1870-1949: NBER historical database (output of main crops)

1950-2004: Chained quantity index of value added in agriculture, Bureau of Economic Analysis .

\section{Manufacturing Output}

1870-1949: Balke and Gordon (1989), kindly communicated by the authors.

1950-2004: Chained quantity index of value added in manufacturing, Bureau of Economic Analysis . 


\section{Transportation and Communications Output}

1870-1949: Balke and Gordon (1989), kindly communicated by the authors.

1950-2004: Chained quantity index of value added in transportation and information industries, Bureau of Economic Analysis .

\section{Construction Activity}

1870-1949: Kuznets' construction series spliced with the Gottlieb/BLS counterpart, as reported in Balke and Gordon (1989), kindly communicated by the authors.

1950-2004:Chained quantity index of value added in construction, Bureau of Economic Analysis

\section{Machinery Investment}

1870-1949: Kuznets' durable producers' output series (with 5-year moving average unraveled), kindly provided by Christina Romer..

1950-2004: Bureau of Economic Analysis.

\section{Central Government Expenditures and Revenues}

1870-1958: Mitchell, op cit..

1959-2004: IFS.

\section{Narrow (M0) and Broad Money (M2)}

1870-1970: Bureau of Economic Analysis, Historical Statistics of the United States.

1970-2004: Haver Analytics.

\section{CPI}

1870-1913: Catão and Solomou (2005).

1914-1947: Balke and Gordon (1989)

1948-2004: IFS.

\section{Export and Import volumes and Net Barter Terms of Trade:}

1870-1913: Catão and Solomou (2005), op.cit.

1914-1959: Bureau of Economic Analysis, Historical Statistics of the United States. 1960-2004: IFS. 


\section{Current Account Balance:}

1870-1959: Bureau of Economic Analysis, Historical Statistics of the United States. Calculated by adding the balance of goods and services (series U15) plus net private and government transfers (series U16 and U17).

1960-2004: IFS.

\section{Real Effective Exchange Rate}

1870-1913: Catão and Solomou (2005).

1914-2004: CPI-based geometric weighted averages of the United State's real bilateral exchange rates with 17 largest trading partners (covering over no less than two thirds of its visible trade before World War II and no less than 80 percent onwards). Fisher ideal indices were derived for the sub-periods 1914-1946 and 1946-2004 (based on 1913 and 1938, and 1970 and 2000 weights respectively), and then spliced at 1946. Nominal exchange rates for the whole post-WWII period are market rates underlying Carmen M. and Kenneth S. Rogoff, 2004, "The Modern History of Exchange Rate Arrangements: A Reinterpretation," Quarterly Journal of Economics, CXIX, No.1, pp.1-48.

\section{Wages}

1870-1944: Jeffrey G. Williamson, "The Evolution of Global Labor Markets Since 1830," Explorations in Economic History, 32 (2), 1995, pp. 141-96.

1945-2004: Hourly compensation in manufacturing from IFS deflated by CPI from the same source.

\section{Foreign 10-year bill rate}

1870-1953: Sidney Holmer and Richard Sillas, 1996, A History of Interest Rates, Rutgers.

1954-2004: IFS.

\section{Foreign Output}

Real GDP of Australia, Canada, UK, France, Germany, Italy and Japan in 1990 PPP constant dollars from Maddison (2003) extended with IFS data through 2004.

\section{Population at mid-year}

1870-1960: Maddison (2003).

1961-2004: IFS (2003). 